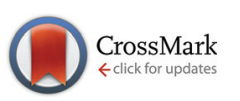

Cite this: Dalton Trans., 2017, 46, 165

\section{Redox trends in cyclometalated palladium(II) complexes $\dagger$}

\author{
Yulia B. Dudkina, ${ }^{a}$ Kirill V. Kholin, ${ }^{a}$ Tatyana V. Gryaznova, ${ }^{a}$ Daut R. Islamov, ${ }^{a, b}$ \\ Olga N. Kataeva, ${ }^{a, b}$ Ildar Kh. Rizvanov, ${ }^{a}$ Alina I. Levitskaya, ${ }^{a}$ Olga D. Fominykh, ${ }^{a}$ \\ Marina Yu. Balakina, ${ }^{a}$ Oleg G. Sinyashin ${ }^{a}$ and Yulia H. Budnikova*a,b
}

Received 29th September 2016, Accepted 18th November 2016

DOI: $10.1039 / \mathrm{c} 6 \mathrm{dt} 03786 \mathrm{k}$

www.rsc.org/dalton

\begin{abstract}
A series of diverse binuclear and mononuclear cyclometalated palladium(॥) complexes of different structure was investigated by electrochemical techniques combined with density functional theory (DFT) calculations. The studies including cyclic and differential pulse voltammetry, X-ray structure analysis and quantum chemical calculations revealed a regularity of the complexes oxidation potential on the metalmetal distance in the complexes: the larger $\mathrm{Pd}-\mathrm{Pd}$ distance, the higher oxidation potentials. The reduction potentials feature unusually high negative values while no correlation depending on the structure could be observed. These results are in a good agreement with the electron density distribution in the complexes. Additionally, ESR data obtained for the complexes upon oxidation is reported.
\end{abstract}

\section{Introduction}

Palladium compounds are known as the most attractive catalysts for many important organic transformations. ${ }^{1-7}$ As these reactions involve organometallic intermediates in different oxidation states (which are generally redox active), the catalytic cycles can be elucidated by electrochemical methods. To date this strategy was successfully used to study $\operatorname{Pd}(\mathrm{II}) / \mathrm{Pd}(0)$ crosscouplings. ${ }^{3}$ Contrariwise, electrochemical data for $\mathrm{Pd}(\mathrm{II}) / \mathrm{Pd}(\mathrm{III})$ and $\mathrm{Pd}(\mathrm{II}) / \mathrm{Pd}(\mathrm{IV})$ redox couples and for reactions based on these shuttles is extremely poor.

Cyclometalated palladium(II), (III), (IV) complexes are proposed to be key intermediates in oxidative ligand-directed aromatic $\mathrm{C}-\mathrm{H}$ functionalizations. ${ }^{4,5}$ Although this approach is adapted to introduce diverse functional groups into aromatic substrates in $\mathrm{C}\left(\mathrm{sp}^{2}\right)-\mathrm{H}$ halogenation, acetoxylation, arylation and some other reactions, ${ }^{6,7}$ examples of effective formation of carbon-phosphorus and carbon-fluoroalkyl bonds are still rare $^{8-10}$ although compounds with these structure units are important and relevant as pharmaceuticals. ${ }^{11-14}$

\footnotetext{
${ }^{a}$ A.E. Arbuzov Institute of Organic and Physical Chemistry, Kazan Scientific Center, Russian Academy of Sciences, 8 Arbuzov str., Kazan 420088, Russian Federation. E-mail: yulia@iopc.ru

${ }^{b}$ Kazan (Volga Region) Federal University, A.M. Butlerov Chemical Institute, 18 Kremlevskaya str., Kazan, 420008, Russian Federation

$\dagger$ Electronic supplementary information (ESI) available: Cyclic and differential pulse voltammograms of palladacycles reductions and oxidations, experimental and simulated ESR spectra, results of topological analysis based on QTAIM, NMR spectra of new compounds. CCDC 1488860-1488862. For ESI and crystallographic data in CIF or other electronic format see DOI: 10.1039/c6dt03786k
}

Electrochemical properties of cyclopalladated complexes are described only in few works ${ }^{15-19}$ and no generalization has been made for them, whereas, the redox properties are expected to specify reactivity of the complexes in $\mathrm{C}-\mathrm{H}$ functionalization processes. The most explicit information can be provided by electrochemical techniques amplifying with DFT calculations which were found very advantageous in mechanistic studies of palladacycles transformations during $\mathrm{C}-\mathrm{H}$ functionalizations. ${ }^{20-24}$ In the recent work, ${ }^{19}$ the joint use of spectroscopic (including cyclic voltammetry (CV)) methods and quantum chemical calculations revealed features of electron density distribution within mono- and binuclear palladacycles with 2-phenylpyridine ligand where palladium oxidation states were (II), (III) and (Iv). Recently, Musaev and co-workers explored the factors impacting the stability and reactivity of dimeric $\mathrm{Pd}(\mathrm{II})$ complexes in $\mathrm{C}-\mathrm{H}$ functionalization catalysis. ${ }^{25}$ In this theoretical study, it was assumed that binuclear complexes require a higher $\mathrm{C}-\mathrm{H}$ activation barrier than mononuclear ones, but no experimental factors and data were analyzed.

The purpose of this paper is to reveal structure-electrochemical properties correlation for cyclometalated palladium(II) complexes. We performed analysis of electrochemical properties in a series of binuclear and mononuclear palladacycles with diverse bridging groups (acetate, trifluoroacetate, chloride, phosphonate) and $\mathrm{C}^{\wedge} \mathrm{N}$ ligands (2-phenylpyridine (phpy), benzo[h]quinolone (bhq) and 1-phenylpyrazole (phpz)) presented in Fig. 1. The complexes were investigated by voltammetry techniques and DFT calculations aiming to find out regularities of their oxidation and reduction, stability and electron density distribution in different oxidation states 

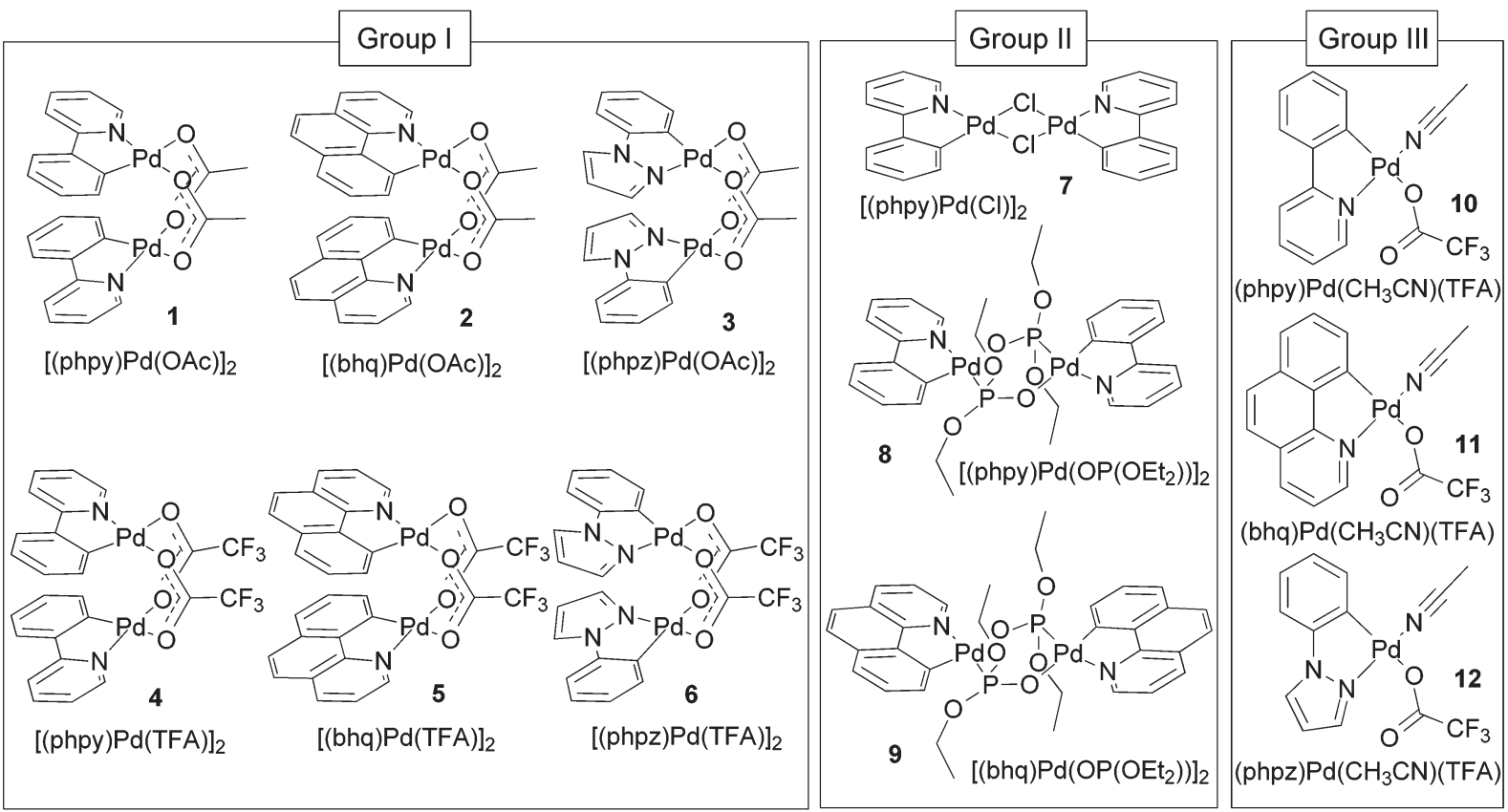

Fig. 1 Selected cyclometalated palladium complexes.

$\operatorname{Pd}(\mathrm{II}) / \mathrm{Pd}(\mathrm{III}) / \mathrm{Pd}(\mathrm{IV})$, influence of ligand, bridging group and solvent nature on the redox properties. Because the oxidized forms of the complexes might be ESR-active $\operatorname{Pd(III)~species,~all~}$ compounds were also examined in ESR experiments.

\section{Results and discussion}

In this work a wide scope of palladacycles are investigated, among which complexes 5, 6, 11, 12 have not been described earlier. Depending on the structure type, nuclearity and (for binuclear compounds) position of the cyclometalated fragments relative to each other the complexes were divided into three groups which are expected to show different redox behavior. The groups are: binuclear complexes of clamshell (I group) and unfolded (group II) geometries, mononuclear complexes (group III) (Fig. 1).

\section{Synthesis and X-ray crystal structure study}

Clamshell carboxylate bimetallic palladacycles 1-6 were obtained by literature procedures from palladium acetate or trifluoroacetate precursors and corresponding $\mathrm{C}^{\wedge} \mathrm{N}$ ligands (Fig. 2a and b). ${ }^{15,18,26,27}$ Structure and reactivity are well-studied for acetate derivatives $\mathbf{1 - 3}$ and trifluoroacetate $\mathbf{4 .}^{18,27-29}$ The single-crystal X-ray structures of the new binuclear trifluoroacetates 5, 6 shown in Fig. 3 and 4 confirm their clamshell geometry similar to that of $\mathbf{1 - 4}$, where two cyclopalladated motifs are located one over another. The Pd-Pd distance (ranging 2.842-2.892 $\AA$ ) is less than the sum of their van der Waals radii (3.26 ̊); in trifluoroacetates 4-6 it is slightly larger compared to the acetates 1-3 $(\sim 0.03 \AA)$ due to electron-
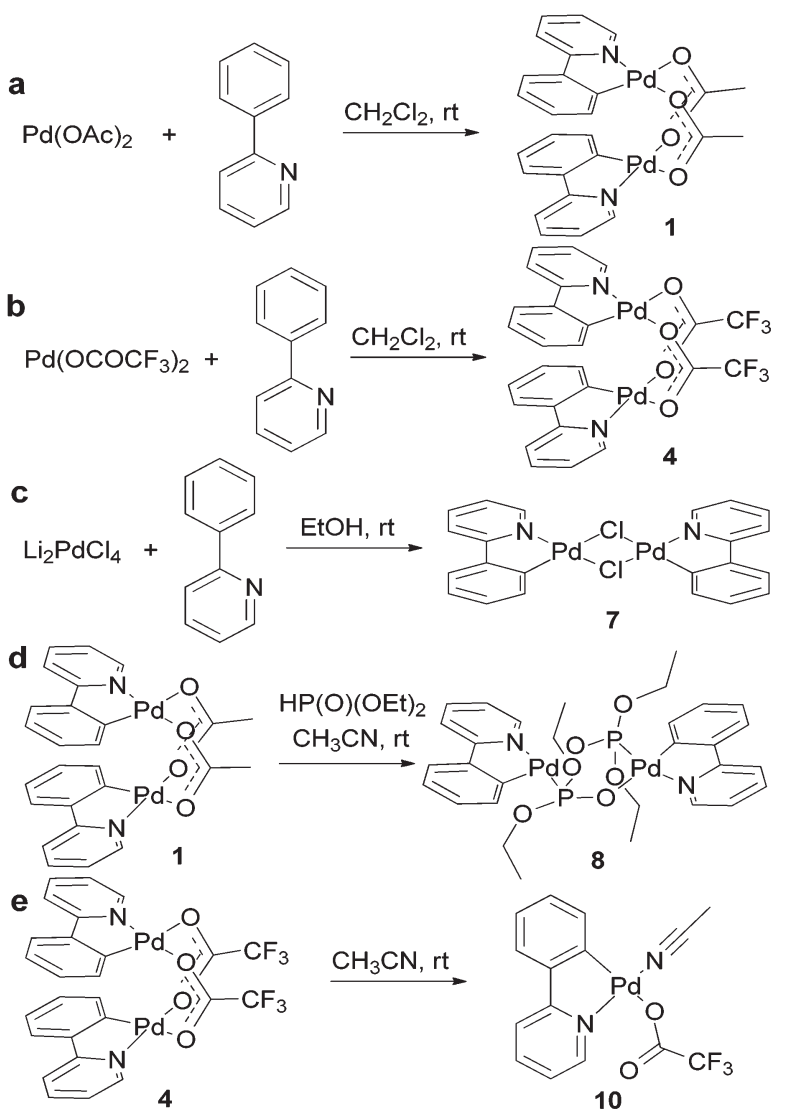

Fig. 2 Syntheses of palladacycles with different bridging groups illustrated by complexes with 2-phenylpyridine ligand. 


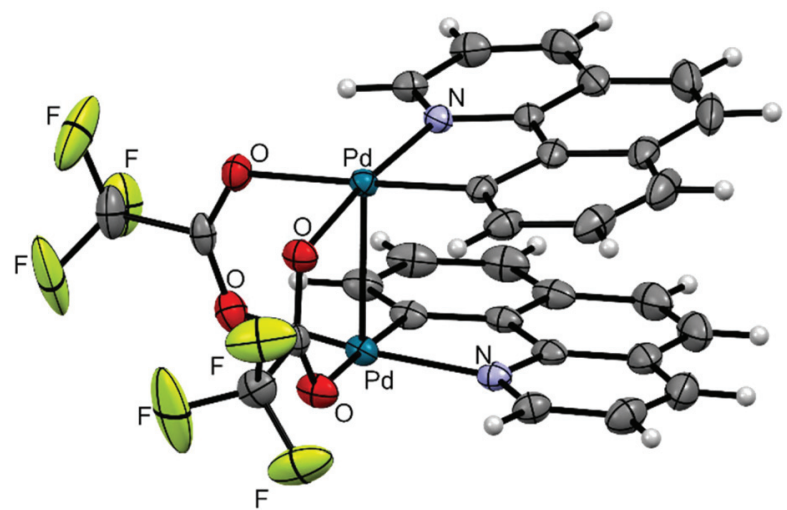

Fig. 3 ORTEP diagram of 5; thermal ellipsoids are drawn at $50 \%$ probability level.

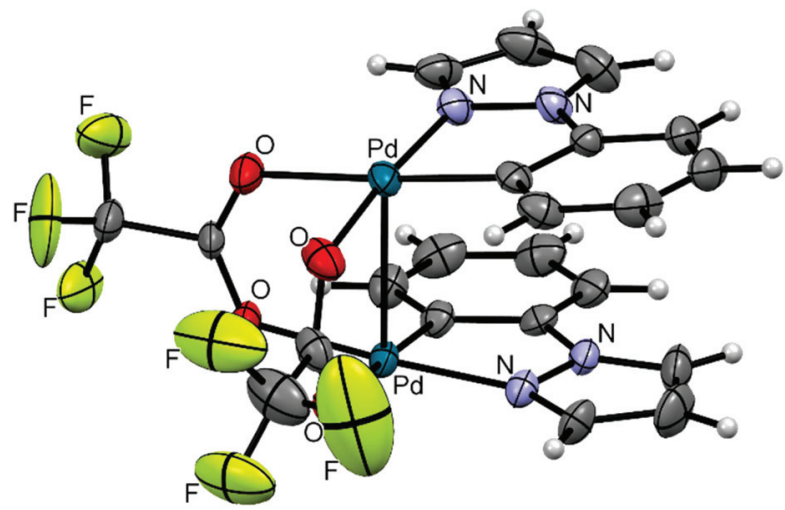

Fig. 4 ORTEP diagram of 6 ; thermal ellipsoids are drawn at $50 \%$ probability level.

withdrawing effect of the $\mathrm{CF}_{3}$-group. The interfacial angle between two cyclometalated units is almost the same in 1-6 and ranges between $15.2-18.5^{\circ}$. The Group I palladacycles feature metal-metal interactions and bond order of $0.10-0.15$ between two palladium atoms. ${ }^{27,30}$

Complexes 7, 8, and 9 belong to the Group II as unfolded palladacycles where no direct metal-metal interactions can be observed but the palladium atoms can influence one another in redox processes. Palladacycle 7 was synthesized from $\mathrm{Li}_{2}\left[\mathrm{PdCl}_{4}\right]$ treated with phpy ligand ${ }^{27}$ (Fig. 2c); our structural and electrochemical data for 7 agree with the previously reported. ${ }^{27}$ Interestingly, the complex reveals almost flat geometry with $1.2^{\circ}$ interfacial angle and $3.494 \AA$ Pd-Pd distance. Treatment of acetates 1, 2 with diethyl- $H$-phosphonate in $\mathrm{CH}_{3} \mathrm{CN}$ affords 8 and 9, respectively (Fig. 2d). Recrystallization of both complexes from $\mathrm{CH}_{3} \mathrm{CN}$ or $\mathrm{CH}_{2} \mathrm{Cl}_{2}$ solutions produces the same dimeric structures. The synthetic procedure, detailed electrochemical study of $\mathbf{8}$ and $\mathbf{9}$ (in solid state and in $\mathrm{CH}_{3} \mathrm{CN}$ solution) and the X-ray structure of $\mathbf{8}$ have been already discussed earlier in our works. ${ }^{31,32}$ The X-ray structure of complex 9 is depicted in Fig. 5. The Pd-Pd distances in 8 and

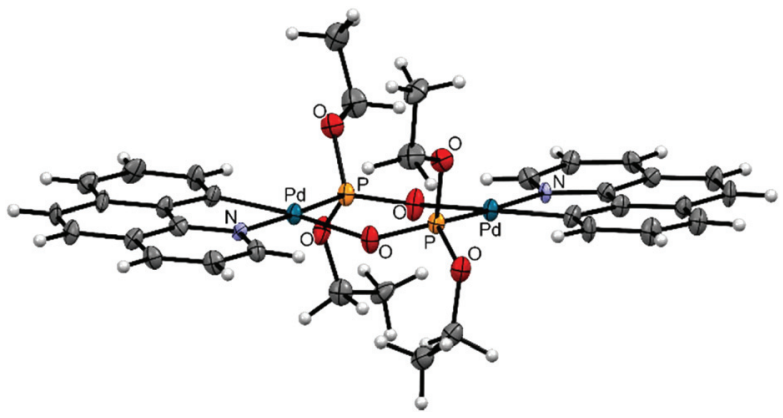

Fig. 5 ORTEP diagram of 9; thermal ellipsoids are drawn at 50\% probability level.

9 are 4.332 and $4.328 \AA$, the interfacial angles are 9.1 and $6.3^{\circ}$, respectively.

Recently, we demonstrated that trifluoroacetate dimer 4 forms mononuclear $\mathbf{1 0}$ being dissolved in/recrystallized from acetonitrile (Fig. 2e); and the redox properties of the monoand binuclear forms differ significantly. ${ }^{18}$ Likewise, trifluoroacetates 5, 6 turn into mononuclear 11 and 12 in $\mathrm{CH}_{3} \mathrm{CN}$ solutions, although no crystals suitable for X-ray analysis could be obtained. Interestingly, the solubility of phpy and phpz derivatives 4 and 6 in $\mathrm{CH}_{3} \mathrm{CN}$ is very high $(\sim 0.2 \mathrm{M})$ while complex 5 with bhq ligand is significantly less soluble ( $\sim 0.05 \mathrm{M})$. Complexes 10-12 constitute the Group III palladacycles with one metal atom per complex molecule.

\section{Electrochemical study}

Electrochemical properties of palladacycles 1-12 were investigated in $\mathrm{CH}_{3} \mathrm{CN}$ and $\mathrm{CH}_{2} \mathrm{Cl}_{2}$ solvents due to their broad potential range capable with oxidative and reductive measurements and the ability to examine the reversible transformation of binuclear and mononuclear forms of the trifluoroacetate complexes and its effect on the redox potentials. It should be mentioned, complex 7 does not undergo monomerization in $\mathrm{CH}_{3} \mathrm{CN}^{33}$ Acetate- and phosphonate-bridged complexes also remain the dimeric structure in both solvents that is proved by the similarity of cyclic voltammograms in $\mathrm{CH}_{3} \mathrm{CN}$ and $\mathrm{CH}_{2} \mathrm{Cl}_{2}$ solutions and in solid state (carbon paste electrode) (ref. 32 and herein).

Cyclic voltammetry studies are known for $\mathbf{1}$ and $\mathbf{4}$ in $\mathrm{CH}_{2} \mathrm{Cl}_{2}$ and $\mathrm{CH}_{3} \mathrm{CN},{ }^{17}$ for 2 in $\mathrm{THF}^{15,16}$ and for 7 in $\mathrm{CH}_{3} \mathrm{CN} .{ }^{17}$ Earlier we already reported electrochemical properties of 1, 4, 10 (in $\mathrm{CH}_{2} \mathrm{Cl}_{2}$ and $\mathrm{CH}_{3} \mathrm{CN}$ ) ${ }^{18}$ and $\mathbf{8 ,} 9$ (solid state, $\mathrm{CH}_{3} \mathrm{CN}$ ). ${ }^{31,32}$ Notably only oxidation processes are of interest in these works. Therefore, the goal of this work is to obtain and analyze redox behavior of a wide scope of palladacycles both in oxidative and reductive conditions.

For all palladacycles 1-12 oxidation occurs in multiple steps as illustrated in Fig. 6 and 7. The curves are very similar (number of oxidation steps, reversibility) for the compounds with the same bridging groups in the same solvent. The first oxidation step is a one-electron process for monomeric complexes and a two-electron one for all dimeric palladacycles. ${ }^{18,19}$ 


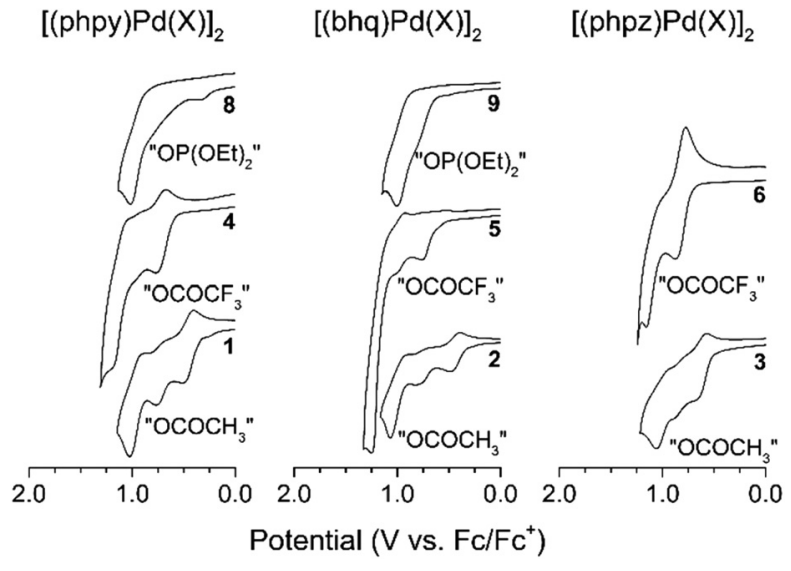

Fig. 6 Cyclic voltammograms of palladacycles in $\mathrm{CH}_{2} \mathrm{Cl}_{2}$.

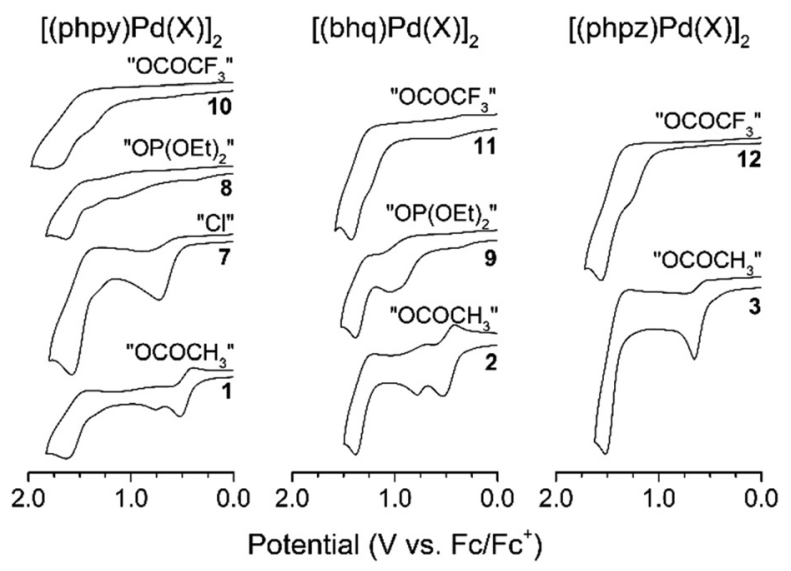

Fig. 7 Cyclic voltammograms of palladacycles in $\mathrm{CH}_{3} \mathrm{CN}$.

For 9 the first oxidation peak consists of two overlooped peaks at close potentials. Free ligands oxidize at significantly higher potentials $\left(\mathrm{V} v s . \mathrm{Fc}^{+} / \mathrm{Fc}\right): 1.70$ (phpy), 1.73 (bhq), 1.80 (phpz).

Reversibility of the first oxidations pertains to the carboxylic complexes (I group), while other complexes show fully irreversible oxidation in CV experiments with scan rate from $50 \mathrm{mV} \mathrm{s}^{-1}$ to $10 \mathrm{~V} \mathrm{~s}^{-1}$. This possibly refers to fast following reductive elimination reactions which afford $\mathrm{C}-\mathrm{H}$ phosphorylation and perfluoroacetoxylation products as it was conformed previously $^{18,31,32}$ in a series of bulk electrolysis reactions. Owing the oxidations irreversibility, differential pulse voltammetry (DPV) was used to elucidate the standard potentials $\left(E^{0}, E_{1 / 2}\right.$, $\left.E_{\mathrm{DPV}}\right)$. Data obtained in CV and DPV experiments is summarized in Tables 1 and 2 and is in a good agreement with known literature reports. ${ }^{15-19}$ Although, the first oxidation step consumes two electrons per binuclear palladacycle molecule, the two electron transfers cannot be resolved in neither cyclic or differential pulse voltammograms, that means, the standard electron potential of the two consequent oxidations are very close to each other.

As can be seen, in $\mathrm{CH}_{2} \mathrm{Cl}_{2}$ the first oxidation potential increase in the sequence: acetates (Group I), trifluoroacetates
Table 1 Electrochemical properties of palladacycles in $\mathrm{CH}_{3} \mathrm{CN} / 0.1 \mathrm{M}$ $\mathrm{Bu}_{4} \mathrm{NBF}_{4}, \mathrm{Pt}-$ w.e., potentials are referred vs. $\mathrm{Fc}^{+} / \mathrm{Fc}$ couple (only the first oxidation step is considered)

\begin{tabular}{lllllllll}
\hline & \multicolumn{3}{l}{$E_{\mathrm{ox}}, \mathrm{V}$} & & & & & \multicolumn{2}{c}{$E_{\mathrm{red}}, \mathrm{V}$} \\
\cline { 2 - 5 } \cline { 8 - 10 } Complex & $E_{\mathrm{pa}}$ & $E_{\mathrm{pc}}$ & $\Delta E_{\mathrm{p}}$ & $E_{\mathrm{DPV}}$ & $i_{\mathrm{c}} / i_{\mathrm{a}}$ & & $E_{\mathrm{pc}}$ & $E_{\mathrm{DPV}}$ \\
\hline $\mathbf{1}$ & 0.52 & 0.40 & 0.12 & 0.44 & 0.3 & -2.19 & -2.12 \\
$\mathbf{2}$ & 0.53 & 0.40 & 0.13 & 0.44 & 0.4 & -2.09 & -2.03 \\
$\mathbf{3}$ & 0.65 & 0.49 & 0.16 & 0.58 & 0.3 & -2.54 & -2.37 \\
$\mathbf{7}$ & 0.73 & - & - & 0.63 & - & -1.91 & -1.85 \\
$\mathbf{8}$ & 1.12 & - & - & 1.00 & - & -2.40 & -2.35 \\
$\mathbf{9}$ & 0.92 & - & - & 0.82 & - & -2.26 & -2.19 \\
$\mathbf{1 0}$ & 1.40 & - & - & 1.32 & - & -1.77 & -1.69 \\
$\mathbf{1 1}$ & 1.26 & - & - & 1.19 & - & -1.69 & -1.61 \\
$\mathbf{1 2}$ & 1.28 & - & - & 1.20 & - & -1.90 & -1.71 \\
& & & & & & &
\end{tabular}

Table 2 Electrochemical properties of palladacycles in $\mathrm{CH}_{2} \mathrm{Cl}_{2} / 0.1 \mathrm{M}$ $\mathrm{Bu}_{4} \mathrm{NBF}_{4}, \mathrm{Pt}-$ w.e., potentials are referred vs. $\mathrm{Fc}^{+} / \mathrm{Fc}$ couple (only the first oxidation step is considered)

\begin{tabular}{lllllllll}
\hline & \multicolumn{3}{l}{$E_{\mathrm{ox}}, \mathrm{V}$} & & & & & \multicolumn{2}{c}{$E_{\text {red }}, \mathrm{V}$} \\
\cline { 2 - 5 } \cline { 6 - 7 } Complex $^{a}$ & $E_{\mathrm{pa}}$ & $E_{\mathrm{pc}}$ & $\Delta E_{\mathrm{p}}$ & $E_{\mathrm{DPV}}$ & $i_{\mathrm{c}} / i_{\mathrm{a}}$ & & $E_{\mathrm{pc}}$ & $E_{\mathrm{DPV}}$ \\
\hline $\mathbf{1}$ & 0.51 & 0.39 & 0.12 & 0.42 & 0.7 & -2.33 & -2.26 \\
$\mathbf{2}$ & 0.49 & 0.38 & 0.11 & 0.40 & 0.8 & -2.20 & -2.14 \\
$\mathbf{3}$ & 0.68 & 0.56 & 0.13 & 0.58 & 0.3 & -2.60 & -2.47 \\
$\mathbf{4}$ & 0.77 & 0.66 & 0.11 & 0.68 & 0.2 & -2.08 & -1.92 \\
$\mathbf{5}$ & 0.76 & - & - & 0.69 & - & -1.95 & -1.84 \\
$\mathbf{6}$ & 0.83 & 0.73 & 0.10 & 0.75 & 0.5 & -2.02 & -1.81 \\
$\mathbf{8}$ & 0.78 & - & - & 0.73 & - & -2.51 & -2.43 \\
$\mathbf{9}$ & 0.80 & - & - & 0.74 & - & - & -2.29
\end{tabular}

${ }^{a}$ Data for complex 7 is unavailable due to its extremely low solubility in $\mathrm{CH}_{2} \mathrm{Cl}_{2}$.

(Group I) and phosphonates (Group II). In $\mathrm{CH}_{3} \mathrm{CN}$ the sequence is different: acetates (Group I) (earliest to oxidize), chlorides (Group II), phosphonates (Group II), trifluoroacetates (Group III) (hardest to oxidize). The oxidation sequence is strongly affected by the palladacycles geometry, particularly the distance between the palladium atoms. The Pd-Pd distance increases in the complexes in passing from clamshell geometry 1-6 to unfolded 7-9 and mononuclear 10-12 structures; consequently, the oxidation potential increases either. The most striking instance is the potential difference $\Delta E_{\mathrm{pa}}$ between acetates and trifluoroacetates palladacycles in both solvents: in $\mathrm{CH}_{2} \mathrm{Cl}_{2} \Delta E_{\mathrm{pa}}=0.15-0.27 \mathrm{~V}$ (due to trifluoroacetate electron-withdrawing effect); in $\mathrm{CH}_{3} \mathrm{CN} \Delta E_{\mathrm{pa}}=$ $0.63-0.88 \mathrm{~V}$ (due to additivity of the structure change and trifluoroacetate electron-withdrawing effect).

To show the revealed trend is a general principle we broaden the scope of palladium complexes with closely related to the palladacycles of Group I $\mathrm{Pd}_{2}$-systems with $\mathrm{N}^{\wedge} \mathrm{C}^{\wedge} \mathrm{N}$ bridging ligands ${ }^{34-39}$ (Fig. 8). These complexes feature metal-metal interaction and exist as two structure isomers: paddlewheel (four bridging ligands) and clamshell (two bridging and two chelating ligands). The former is characterized with shorter Pd-Pd distances and, therefore lower oxidation potential 


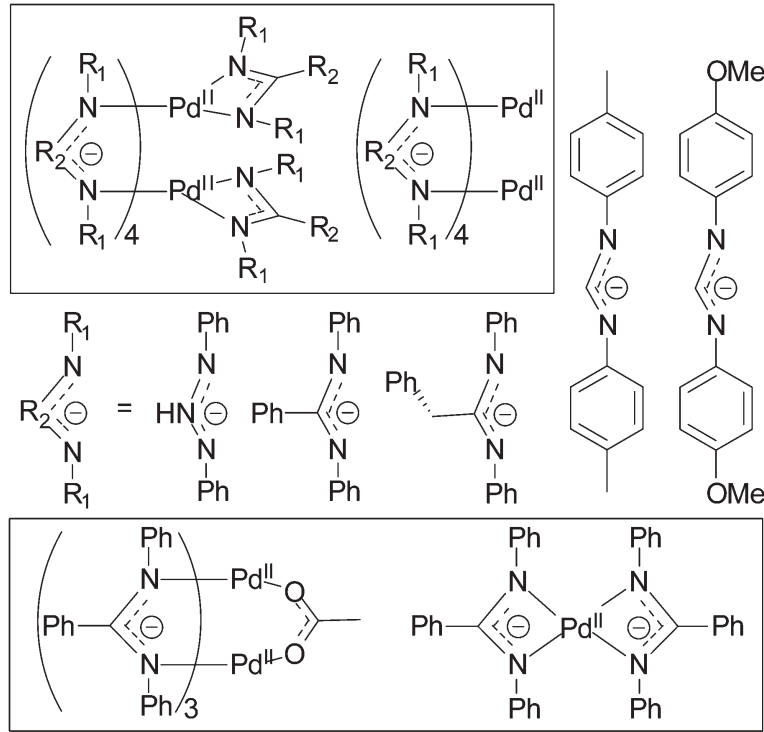

Fig. 8 Palladium complexes with $\mathrm{N}^{\wedge} \mathrm{C}^{\wedge} \mathrm{N}$ ligands.

values. Owing the dissimilarity of the literature data (the complexes are characterized either by oxidation peak potential $E_{\mathrm{p}}(\mathrm{CV})$ or half-wave potential $E_{1 / 2}(\mathrm{DPV})$ ), both parameters were used to illustrate the trend in Fig. 9.

The electrochemical reduction of cyclopalladated complexes is firstly considered in this work. All of them werefound to reduce at unusually high negative potentials (from -1.7 to $-2.6 \mathrm{~V}$ ) (Tables 1 and 2; ESI Fig. S1-S4†). No regularities could be observed in these processes depending on the Pd-Pd distances or any other parameters (ESI, Fig. S7 $\dagger$ ), except an apparent relative ease of reduction of trifluoroacetate dimers compared to the acetate complexes $(\Delta E=0.3-0.6 \mathrm{~V})$ that occurs due to trifluoroacetate electron-withdrawing effect.
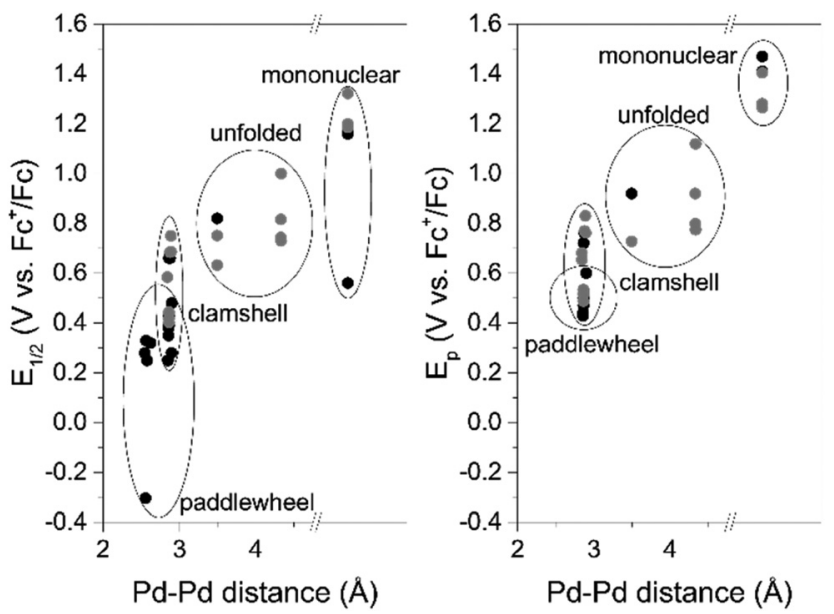

Fig. 9 Plots illustrating the dependence of palladium complexes first oxidation peak potential(v) on Pd-Pd distance (Å). The potentials obtained by DPV (relative to $E_{1 / 2}$ ) are presented on the left plot (a), the ones obtained by $C V\left(E_{p}\right)$ - on the right plot (b). Our data is marked with grey; literature data is marked with black.

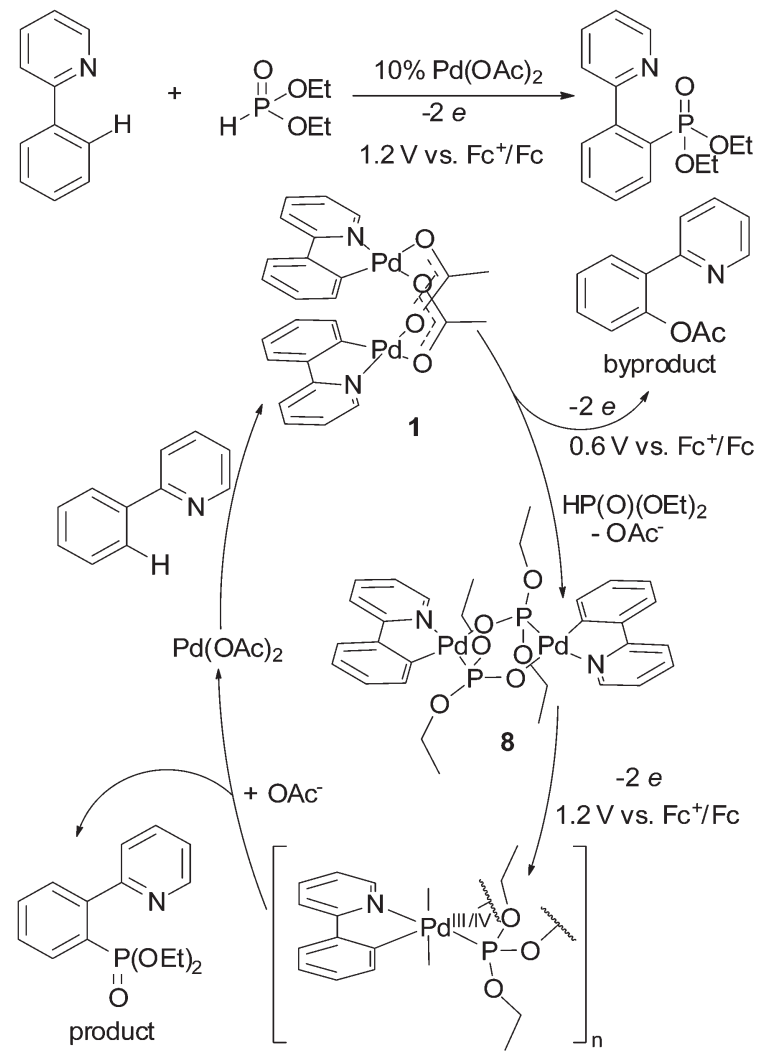

Fig. 10 Catalytic cycle of 2-phenylpyridine phosphorylation illustrating importance of electrolysis potential.

The revealed regularity in oxidation chemistry of cyclopalladated complexes might be useful to determine conditions in ligand-directed $\mathrm{C}-\mathrm{H}$ functionalization reactions. For example, as phosphonate-bridged palladacycles are oxidized significantly more difficult than acetate-bridged ones (Tables 1 and 2), the reactivity of both complexes (key intermediates) should be considered in $\mathrm{C}-\mathrm{H}$ phosphorylation reaction; for example, phosphorylation of 2-phenylpyridine with $H$-phophonates catalyzed by palladium acetate (Fig. 10). ${ }^{8,9,31}$ Selective C-H phosphonation requires the correct choice of an oxidant (or electrolysis potential) to promote oxidation of complex 8. In the case of "weak" oxidant (low electrolysis potential) oxidation of $\mathbf{1}$ is the dominant process resulting in formation of acetoxylated phenylpyridine byproduct. The problem to find an appropriate chemical oxidant likely explains the low yields and very few $\mathrm{C}-\mathrm{H}$ phosphonation reactions in the literature.

\section{ESR study}

Aiming to get more information about possible high-valent intermediates formed upon oxidation of cyclometalated palladium(II) complexes, a set of ESR experiments with different substrate concentrations, solvents $\left(\mathrm{CH}_{2} \mathrm{Cl}_{2} / \mathrm{CH}_{3} \mathrm{CN}\right)$ and varying temperatures was carried out. The palladacycles were tested to give an ESR signal being oxidized in a potentiostatic mode (at the first oxidation peak potential) at platinum working electrode at $275 \mathrm{~K}$; as the signal reached the 


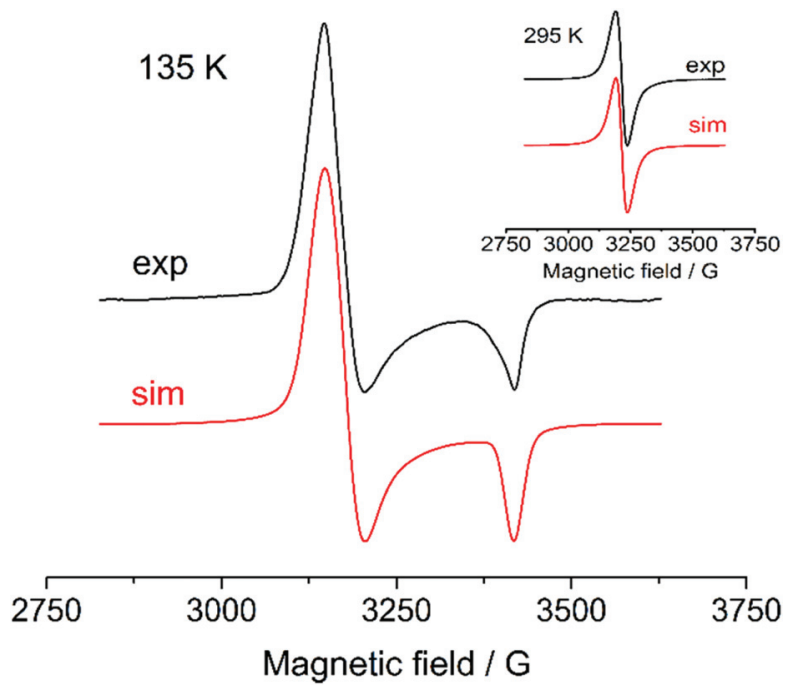

Fig. 11 ESR spectra obtained upon oxidation of $0.1 \mathrm{M} 1$ in $\mathrm{CH}_{2} \mathrm{Cl}_{2}$ at $135 \mathrm{~K}$ and $295 \mathrm{~K}$ (inset). The simulation parameters are provided in Table 3.

maximum value during the electrolysis the temperaturedependent measurements were performed. ESR signals were obtained only for Group I complexes in $\mathrm{CH}_{2} \mathrm{Cl}_{2}$ (Fig. 11; ESI Fig. S10-S21 $\dagger$ ) that corresponds with their reversible oxidations in voltammograms. The fact that no ESR signals were registered for the complexes of Group II and III is likely explained by higher rates of reductive elimination reaction of high-valent palladacycles forming products of $\mathrm{C}-\mathrm{H}$ substitution. Instability of high-valent cyclopalladated intermediates formed from these complexes is also confirmed by irreversibility of their oxidations (Fig. 5, 6 and Tables 1,2).

At room temperature and concentration $0.005 \mathrm{M}$ complexes 1-6 give similar isotropic metal-centered ESR signal. Although the ESR line is single its simulation is a sum of an unresolved hyperfine structure from ${ }^{105} \mathrm{Pd}(22.3 \%$ abundance $)$ and a singlet from zero nuclear spin Pd atoms (ESI Fig. S8†). At that, anisotropy of HFI linewidth should be regarded that leads to poor precision in estimating of linewidth and HFI constants. Solutions of trifluoroacetates 4-6 show slightly larger $g$-factors and lower constants of hyperfine interaction with palladium nuclears compared to acetates 1-3 (Table 3). The increase of the $g$-factor values occurs due to decrease in covalence of metal-ligand bonding and corresponds to electron-withdrawing trifluoroacetate group.

Decreasing the temperature, integral intensity of the critically diminishes down to the noise level. Only for $\mathbf{1}$ and $\mathbf{2}$ we were able to observe ESR signals of the frozen solutions at $0.005 \mathrm{M}$ concentration. To obtain low-temperature spectra which intensity is enough for reliable simulations the concentration was significantly increased up to $0.1 \mathrm{M}$ (Fig. 11). The resulted frozen solution spectra show axial symmetry of the metal center; the magnetic resonance constants are given in Table 3. Unexpectedly, the high-concentrated solutions exhibit parallel and perpendicular components in ESR spectra even at $295 \mathrm{~K}$ and lowering the temperature affects in increasing the anisotropy (ESI, Fig. S9† illustrates the feature by comparing normalized ESR spectra of 4 with concentrations 0.005 and $0.1 \mathrm{M}$ at $295 \mathrm{~K}$ ).

Anisotropic ESR spectra at temperatures more than $100 \mathrm{~K}$ higher the freezing point is uncommon. Considering the

Table 3 Magnetic resonance parameters of ESR signals obtained upon oxidation of palladacycles 1-6 in dichloromethane: $\Delta H$ [G], a [G]

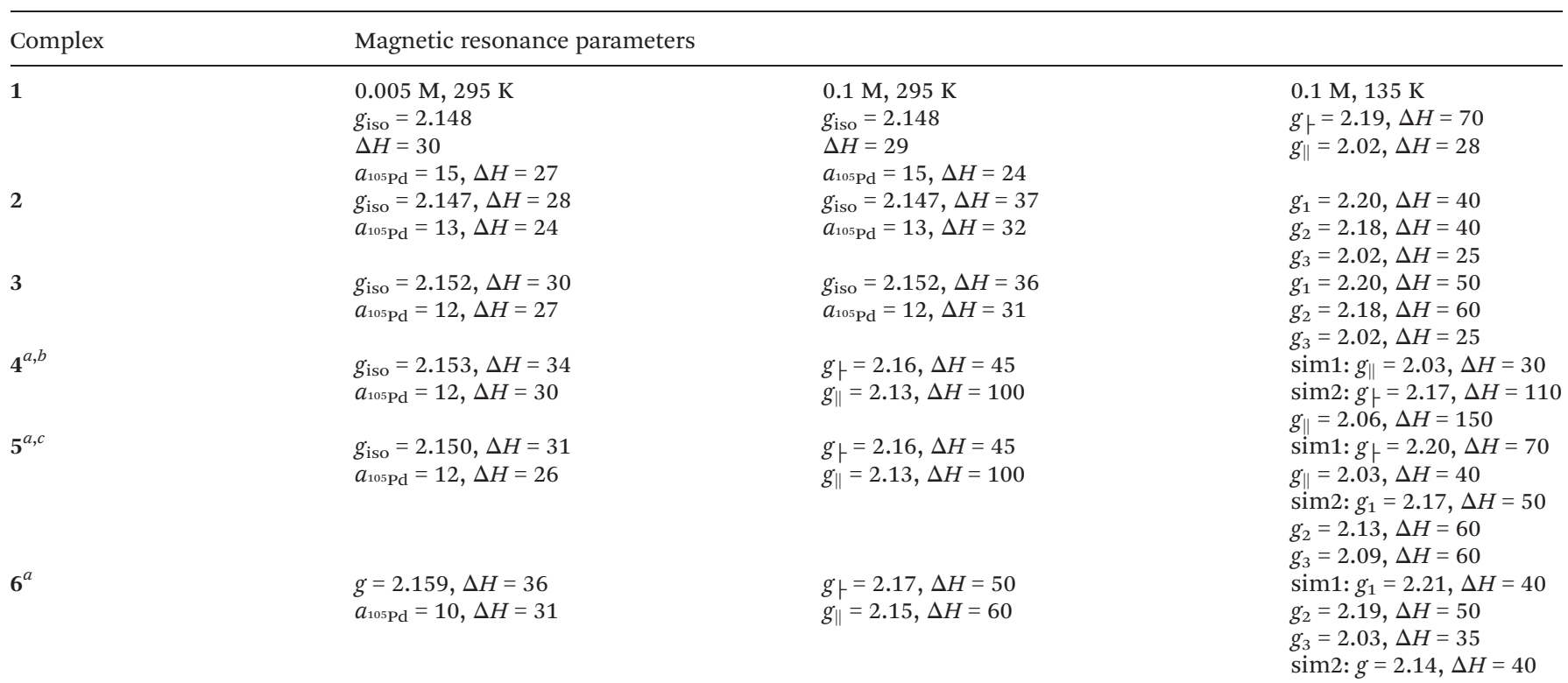

${ }^{a}$ Low-temperature ESR of $0.1 \mathrm{M}$ solutions are simulated as a sum of two spectra ( $\operatorname{sim} 1$ and $\left.\operatorname{sim} 2\right) .{ }^{b} g_{\text {卜 }}$ ( $\left.\operatorname{sim} 1\right)$ cannot be determined in the lowtemperature spectrum. ${ }^{c}$ Low-temperature spectrum was recorded at $155 \mathrm{~K}$. 


$$
\begin{aligned}
n\left[\left(C^{\wedge} N\right)_{2} P d^{\prime \prime} P d^{\prime \prime \prime} X_{2}\right] & \rightleftharpoons\left[\left(C^{\wedge} N\right)_{2} P d^{\prime \prime} P d^{\prime \prime \prime} X_{2}\right]_{n} \\
n\left[\left(C^{\wedge} N\right) P^{\prime \prime \prime \prime} X\right]_{2} & \rightleftharpoons\left[\left(C^{\wedge} N\right) P^{\prime \prime \prime} X\right]_{2 n}
\end{aligned}
$$

Scheme 1 Formation of 1D polymetallic $\mathrm{Pd}(2.5)$ and $\mathrm{Pd}(\mathrm{III})$ structures.

spectral characteristics of paramagnetic species, it is assumed the system is either in solid or liquid state. $g$-Factors and HFI constants of solid state ESR spectra usually depend strongly on the orientation. Anisotropic interactions in low-viscosity solutions are averaged to zero. However, there can be a system state with intermediate viscosity values known as slow axial rotation. The observed phenomenon indicates the ESR-active molecules rotation is "slow" and the increase of rotational diffusion correlation time refers to formation of "large" molecules.

These "large" molecules might be certainly high-valent polynuclear palladium complexes described in recent works ${ }^{16,40}$ since the conditions of voltammetry and ESR experiments, particularly non-coordinating solvent $\left(\mathrm{CH}_{2} \mathrm{Cl}_{2}\right)$ and supporting electrolyte $\left(\mathrm{Bu}_{4} \mathrm{NBF}_{4}\right)$, are similar to those promoting high-valent palladium wires formation (Scheme 1). Although the reports include ESR spectra, no magnetic resonance parameters are described there ${ }^{16}$ Based upon the signals shape the polynuclear complexes are characterized by the same ESR parameters as mono- and binuclear palladacycles. ${ }^{41}$ According the quantum calculations, the bond between two binuclear palladacycled(III) units forms through hybridization of HOMO and $5 \mathrm{p}$ orbital with no unpaired electrons. While authors give ESR spectra of formally polymetallic Pd(III) structures, they mention the EPR spectra of $\operatorname{Pd}(2.5)$ and $\operatorname{Pd}(\mathrm{III})$ wires are very similar at $77 \mathrm{~K}$ and propose a rapid electronic equilibrium between $\operatorname{Pd}(2.5), \operatorname{Pd}(\mathrm{III})$, and $\operatorname{Pd}($ II) species. Thus, the registered spectra belong to $\operatorname{Pd}(2.5)$ wires as polynuclear $\mathrm{Pd}(\mathrm{III})$ and $\mathrm{Pd}(\mathrm{II})$ complexes are not detectable in ESR. Therefore, polynuclear $\operatorname{Pd}(2.5)$ wires are the species giving the spectra we observe.

Furthermore, if the cooling time in our experiments is significantly reduced from gradual cooling during several hours to a sharp freezing in a few seconds, the spectral intensity of frozen solution ESR remains at the same low level. This fact except any influence of chemical processes like possible comproportionation or other reactions and chemical equilibriums. It means the decrease in amount of the paramagnetic centers (the decrease in intensity) with reducing the temperature is supposed to stem from redistribution of paramagnetic centers within polynuclear chains containing both $\mathrm{Pd}(\mathrm{II})$ and $\mathrm{Pd}(\mathrm{III})$ atoms. At higher temperatures there are many $\mathrm{Pd}(\mathrm{II})-\mathrm{Pd}(\mathrm{III})$ units in a chain giving an intensive ESR signal, while at lower temperature $-\mathrm{Pd}(\mathrm{II})_{n}-$ and $-\mathrm{Pd}(\mathrm{III})_{n}-$ clusters are formed within the chain and only $-\mathrm{Pd}(\mathrm{II})-\mathrm{Pd}(\mathrm{III})-$ "joints" produce the signal. The larger clusters, the fewer joints and the lesser intensity. Such phenomena are known in the literature. ${ }^{42,43}$

\section{DFT study}

Study of the palladium(II) complexes by quantum chemistry methods provides more detailed understanding of their redox properties; calculations allow to estimate the frontier orbitals energy which is directly linked to the standard reduction and oxidation potentials. ${ }^{44-50}$ The obtained wave function was used to study the electronic charge density distribution in the molecule space.

Calculations of energy characteristics for the complexes were carried out by the DFT method at B3LYP/TZP-DKH. The applied computational approach allows to adequately solve the problem (with sufficient precision); TZ level basis set provides high accuracy of calculation, in particular, for the ionization potentials the mean absolute deviation (MAD) from the results of precise calculations at DKH-CASSCF/CASPT2 level (the multi-configuration wave function, taking into account the dynamic correlation by the second-order perturbation theory) with very large relativistic bases of natural orbitals ANO does not exceed $0.275 \mathrm{eV}$ for the fourth series elements. ${ }^{51}$ The use of TZP-DKH basis significantly reduces the error, conditioned by the basis set incompleteness compared to the corresponding double-exponential basis DZP-DKH ${ }^{52}$ for which this deviation is $0.876 \mathrm{eV}$ (ref. 51). For the first series elements comprising the complexes MAD does not exceed $0.112 \mathrm{eV}^{53}$ Calculations were performed using the geometry obtained from X-ray diffraction data for complexes 1-10 representing the three structural types. Account of solvent can play a significant role in determining the redox potentials, so the calculation of characteristics of the complexes under study was performed in two solvents $-\mathrm{CH}_{3} \mathrm{CN}$ and $\mathrm{CH}_{2} \mathrm{Cl}_{2}$; the account of the solvent effect was carried out in the framework of polarizable continuum model PCM. ${ }^{54}$

Early research carried out on organic compounds showed a correlation between the standard reduction and oxidation potentials, and the LUMO and HOMO energies. ${ }^{44-50,55-58}$ It was assumed the molecular orbital energies could be calculated directly from cyclic voltammetry results calibrated with ferrocene with a value of $4.8 \mathrm{eV}^{44}$

$$
\begin{aligned}
& E_{\mathrm{HOMO}}=-\left(E\left[1 / 2, \mathrm{ox} v s . \mathrm{Fc}^{+} / \mathrm{Fc}\right]+4.8\right)(\mathrm{eV}), \\
& E_{\mathrm{LUMO}}=-\left(E\left[1 / 2, \text { red } v s . \mathrm{Fc}^{+} / \mathrm{Fc}\right]+4.8\right)(\mathrm{eV}),
\end{aligned}
$$

where the half-wave potential $\left(E_{1 / 2}\right)$ is taken as an excellent approximation of the formal potential $\left(E^{0 \prime}\right)$ of a reversible redox couple, since the diffusion coefficients of the oxidized and reduced species should be approximately equal. ${ }^{59}$

Irreversibility of redox processes does not allow to use these formulae directly for the studied palladium complexes, so the standard oxidation and reduction potentials values obtained by the DPV method were plugged into the formulae to calculate the frontier orbitals energy:

$$
\begin{aligned}
& E_{\mathrm{HOMO}}=-\left(E\left[{ }_{\mathrm{DPV}, \mathrm{ox} v s . \mathrm{Fc}^{+} / \mathrm{Fc}}\right]+4.8\right)(\mathrm{eV}), \\
& E_{\mathrm{LUMO}}=-\left(E\left[{ }_{\mathrm{DPV}, \text { red } v . ~} \mathrm{Fc}^{+} / \mathrm{Fc}\right]+4.8\right)(\mathrm{eV}) .
\end{aligned}
$$

The calculated and experimental HOMO and LUMO energy values are presented in Table 4 . The theoretical values of the HOMO energies correlate well with those estimated in voltammetry experiment. 
Table 4 Palladium complexes frontier orbitals energy values (eV)

\begin{tabular}{|c|c|c|c|c|c|c|c|}
\hline Type & Complex & $\begin{array}{l}E_{\text {Hомо }}, \mathrm{eV} \\
\text { (DPV exp.) }\end{array}$ & $\begin{array}{l}E_{\text {LUMO }}, \text { eV } \\
\text { (DPV exp.) }\end{array}$ & $\begin{array}{l}\Delta E_{\text {(номо-LUмо) }}, \mathrm{eV} \\
\text { (DPV exp.) }\end{array}$ & $\begin{array}{l}E_{\text {Hомо }}, \text { eV } \\
\text { (DFT cal.) }\end{array}$ & $\begin{array}{l}E_{\text {LUMO }}, \text { eV } \\
\text { (DFT cal.) }\end{array}$ & $\begin{array}{l}\Delta E_{\text {(номо-LUмо) }}, \mathrm{eV} \\
\text { (DFT cal.) }\end{array}$ \\
\hline \multicolumn{8}{|c|}{ Acetonitrile } \\
\hline & 3 & -5.38 & -2.43 & -2.95 & -5.39 & -1.52 & -3.87 \\
\hline II & 7 & -5.43 & -2.95 & -2.48 & -6.22 & -2.08 & -4.14 \\
\hline & 8 & -5.80 & -2.45 & -3.35 & -6.08 & -1.77 & -4.31 \\
\hline & 11 & -5.99 & -3.19 & -2.79 & - & - & - \\
\hline & 12 & -6.00 & -3.09 & -3.91 & - & - & - \\
\hline \multicolumn{8}{|c|}{ Dichloromethane } \\
\hline \multirow[t]{4}{*}{ I } & 1 & -5.22 & -2.54 & -2.68 & -5.29 & -2.06 & -3.23 \\
\hline & 2 & -5.20 & -2.66 & -2.54 & -5.31 & -2.14 & -3.17 \\
\hline & 3 & -5.38 & -2.33 & -3.05 & -5.34 & -1.52 & -3.82 \\
\hline & 4 & -5.48 & -2.88 & -2.61 & -5.63 & -2.32 & -3.31 \\
\hline
\end{tabular}

Analysis of calculation results presented in Table 4 shows several tendencies. The HOMO energy values for the Group I complexes are slightly higher than for the Group II complexes. The $\Delta E_{\text {(номо-Lumo) }}$ values tend to increase in series of complexes 1-9; the marked trend being more pronounced in the case of complexes in acetonitrile. The energy difference $\Delta E$ for the Group I complexes comprises from 3.17 to $3.45 \mathrm{eV}$, while for 3 this value is slightly larger. When changing acetonitrile to dichloromethane the $\Delta E$ value decreases slightly (by $\sim 0.05 \mathrm{eV}$ for 1 and 2 ; by $\sim 0.32 \mathrm{eV}$ for 3 ). $\Delta E$ values for complexes of the $\mathrm{II}^{\text {nd }}$ group is considerably greater than for the complexes of the $\mathrm{I}^{\text {st }}$ group. The $\Delta E$ value for monomer 10, which represents the Group III, is comparable with the value for the II type complexes; the difference amounts $0.01 \mathrm{eV}$.

Isodensity plots of the frontier orbitals were built on the basis of the calculated wave functions for complexes 1-10.
It was found that for each group of palladium complexes similar electron density distribution on the HOMO orbitals is typical. Whereas the LUMOs for all the complexes are localized mainly on the aromatic ligand, which explains the high values of the reduction potentials of palladacycles. As can be seen in Fig. 12 by example of complex 3, for the I Group complexes the HOMO maximum density is focused on palladium atoms and captures their neighboring ligand atoms, as for the LUMO, on the contrary, the density is shifted to heterocycles, and there is some coupling between them. Regarding the acetate "tails", they are not involved in binding at all. Analysis of the form of the frontier orbitals of complex 2 suggests there is no overlap of electron clouds in heterocyclic ligands in the case of LUMO, where the conjugated system of ligands is more extended, despite the fact that the distance between the palladium atoms corresponds to estimations made for the other complexes of the Group I.
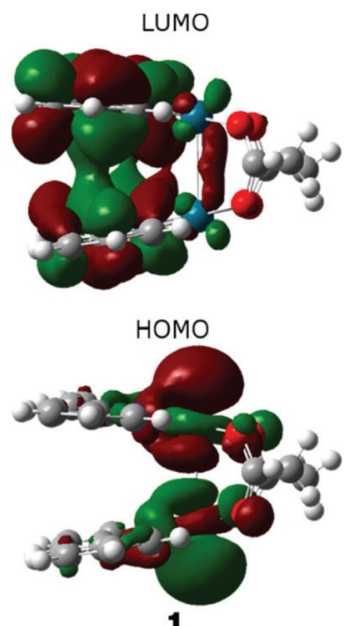

1
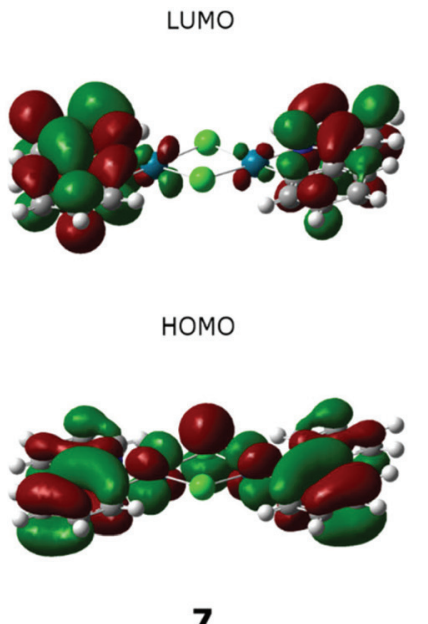

7
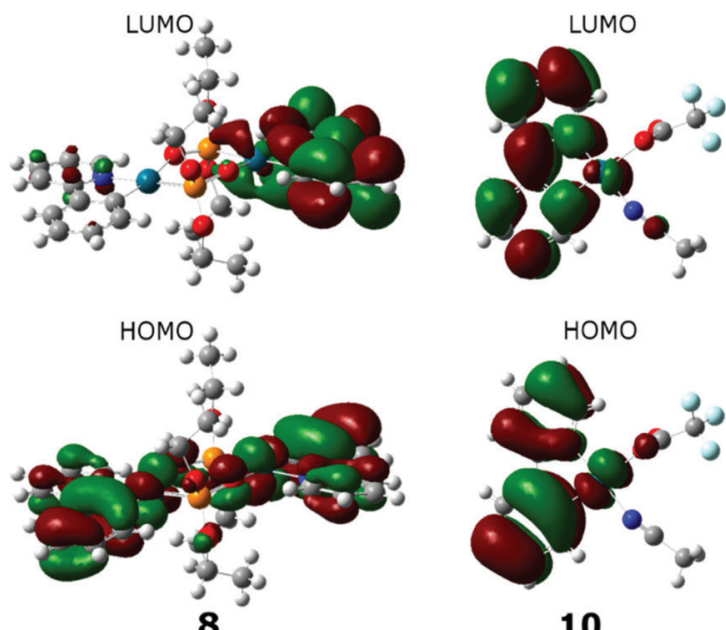

10

Fig. 12 Frontier orbitals isodensity maps for complexes 3, 7, 8 and 10. 
A characteristic feature of the complexes of the II $^{\text {nd }}$ group is the distribution of HOMO electronic density over the entire plane of both cyclopalladated fragments, HOMO captures both the palladium atoms and heterocyclic ligands (it is illustrated by complex 7 in Fig. 12). In the case of LUMO the electron density is shifted predominantly to the periphery of the complex, i.e. to the heterocyclic ligands, some asymmetry in electronic distribution being observed at that. In the case of phosphonate complexes (Fig. 10, complex 8) there is complete asymmetry in the distribution of electron density in LUMO, that is density on one ligand is much higher than on the other. Thus, for the Group II complexes each component of dimeric complex behaves independently, so that the total electron density of the complex is an additive one. As for the complex 10, belonging to the Group III, LUMO electron density is shifted towards the periphery of the heterocycle, while trifluoroacetate and acetonitrile ligands being very weakly involved (Fig. 12).

Thuswise, a correlation between the energy gap value $\Delta E$, the value of oxidation potential and the complex geometry is observed. When passing from the I Group systems (clamshell type) to the II and III Groups (dimers with unfolded structure and mononuclear complexes, respectively) the electron density is shifted from palladium atoms to the aromatic ligand, which is reflected in the shift of the complex oxidation potential toward more positive potentials.

The assumption of the binding between the ligands heterocycles arising due to non-covalent interactions, is supported by the results of the topological analysis of the peculiarities of distribution of electron charge density in the framework of Atoms in Molecules topological analysis QTAIM $^{60}$ (ESI, Fig. S22 and S23 $\uparrow$ ): in the molecular region between the heterocyclic ligands a set of critical points was detected, the values of the electron density and the Laplacian of the charge density in which falling into the range of values typical for the non-covalent binding. ${ }^{61,62}$ Analysis of topological characteristics, obtained by QTAIM method for $\mathbf{3}$ and $\mathbf{4}$ in both solvents, has demonstrated that the electron density and Laplacian of charge density values at the critical points of binding between the ligands are insignificantly larger in case of complex $3 \mathrm{com}$ pared to those for complex $\mathbf{4}$, since the distance between the cycles planes in complex $\mathbf{3}$ is a little bit smaller than that in complex 4. It is interesting to note that in the case of complex 4 ellipticities of critical points are considerably greater than those for 3 independently on the solvent, this fact together with the proximity of the critical points of $(3,-1)$ type and the points in the rings of $(3,+1)$ type indicates tendency to breaking the ligands binding, which apparently can lead to complex monomerization.

\section{Experimental}

\section{General considerations}

Reactions were carried out under ambient atmosphere. All solvents employed were purified and dried according to standard methods prior to use. All chemicals were purchased from commercial suppliers and used as received. NMR experiments were carried out with Bruker spectrometers AVANCE-400 and AVANCE-500. Chemical shifts are reported in the $\delta(\mathrm{ppm})$ scale relative to the residual solvent signals for ${ }^{1} \mathrm{H}$ and ${ }^{13} \mathrm{C}$, to external $\mathrm{C}_{6} \mathrm{~F}_{6}(-164.9 \mathrm{ppm})$ for ${ }^{19} \mathrm{~F}$ NMR spectra. Multiplicities are reported as follows: singlet (s), doublet (d), triplet (t), quartet (q), quintet (quin), sextet (sext), multiplet (m), broad resonance (br); coupling constants in Hz; integration. Mass spectra MALDI were recorded on a UltraFlex III TOF/TOF spectrometer (Bruker Daltonik GmbH, Germany) in a linear negative mode with a solution of molecular sulfur in toluene as a matrix using a metallic target. Laser Nd:YAG, $\lambda=266 \mathrm{~nm}$. FlexAnalysis 3.0 program (Bruker Daltonik GmbH, Germany) was used to process the data. Mass spectra ESI were recorded on a AmazonX spectrometer (Bruker Daltonik GmbH, Germany) in negative and positive mode with capillary voltage $-4500 \mathrm{~V}$. The drying gas was nitrogen of $250{ }^{\circ} \mathrm{C}$ and flow of $81 \mathrm{~min}^{-1}$. Samples of $10^{-6} \mathrm{~g} \mathrm{ml}^{-1}$ concentration in THF or $\mathrm{CH}_{3} \mathrm{CN}$ were used for analysis.

\section{Electrochemistry and ESR}

Voltammograms were recorded with a BASi Epsilon potentiostat/galvanostat (USA) at room temperature dichloromethane or acetonitrile solutions under dry argon atmosphere. All measurements were carried out with $0.1 \mathrm{M} \mathrm{Bu}_{4} \mathrm{NBF}_{4}$ as the supporting electrolyte, platinum working electrode $\left(0.02 \mathrm{~cm}^{2}\right)$, platinum auxiliary electrode, and $\mathrm{Ag} / \mathrm{AgNO}_{3}$ reference electrode. All potentials were referred against the ferrocenium/ ferrocene redox couple.

The ESR spectra were recorded in degassed dichloromethane or acetonitrile solutions $\left(0.1 \mathrm{M} \mathrm{Bu}_{4} \mathrm{NBF}_{4}\right)$ on an apparatus program complex ${ }^{63}$ including an ELEXSYS E500 ESR spectrometer of the X-range and a three-electrode $(\mathrm{Pt})$ cell. The spectra were simulated using the WinSim 0.96 program (developed by NIEHS).

\section{Computational details}

Calculations of palladium complexes under study density functional method (DFT) was used. According to the literature data, the B3LYP hybrid functional allows one to obtain the value of the redox potential in good agreement with the experimental data. ${ }^{64-66}$ Regarding the choice of the basis set, twoexponential or three-exponential bases augmented by polarization and diffuse functions are sufficient for the description of the redox processes. ${ }^{67,68}$ As it is noted in the literature, the choice of basis sets for calculations of the fourth series elements is rather poor. ${ }^{51}$ It is known that for the fourth series elements the relativistic effects can play a significant role. Simplified (convenient) way of accounting for relativistic corrections is to use the relativistic effective core potentials or pseudopotentials (PP), the accuracy of their introduction depends on the method of constructing the core (or the number of electrons, which are regarded as the core ones). Correlation-consistent basis sets for the $\mathrm{Y}_{-} \mathrm{Pd}^{69,70}$ and In-Xe have been developed ${ }^{71,72}$ together with relativistic potentials of 
"small" cores, which explicitly take into account (consider) not only the outer valence shells (nspd), but also "external" core shells $(n-1)$ spd. It is believed that the pseudopotential method is a good approximation to the scalar relativistic calculations ${ }^{73,74}$ which takes into account all of the electrons, but in special cases, such as the topological analysis of the electron density distribution in the molecular system, the use of all-electron basis sets is preferable. ${ }^{51}$ For such cases, one should use basic sets that allow to account the scalar relativistic corrections, thus leading to the change in the description of the relativistic contraction of core orbitals and the corresponding relativistic expansion of the valence orbitals. ${ }^{75}$ In this paper, for the calculation of palladium complexes TZP-DKH basis set ${ }^{51}$ was used, which is a contracted set [9s6p4d2f1g], derived from (20s15p9d2f1g) set of primitive Gaussian functions; ${ }^{76-79}$ the used contraction allows to take into account the scalar relativistic corrections with the DouglasKroll-Hess approach. ${ }^{77-79}$ The calculations were performed with GAUSSIAN 09 program package. ${ }^{80}$

To study the characteristic features of charge density distribution in the complexes under study Quantum Theory of Atoms in molecules (QTAIM) topological analysis ${ }^{60}$ was performed. The topological properties of the molecular charge distribution are characterized by the number and type of charge density $\rho\left(\boldsymbol{r}_{\mathbf{c}}\right)$ critical points, where the gradient of charge density, $\nabla \rho\left(\boldsymbol{r}_{\mathbf{c}}\right)$, vanishes. The critical points, classified according to their rank and signature, can be of four types: $(3 ;-3),(3 ;-1),(3 ;+1),(3 ;+3)$, corresponding to the nuclei positions, the bonds between atoms (both covalent and noncovalent ones), cyclic or cage elements in the molecule, respectively. Rank of a critical point is equal to the number of Hessian eigenvalues; signature of a critical point is equal to the difference between the number of the Hessian positive and negative eigenvalues $\left(\lambda_{1}<\lambda_{2}<\lambda_{3}\right.$ is assumed), having the meaning of charge density curvatures in the directions of Hessian eigenvectors; two derived quantities are the Laplacian of the charge density at bond critical point, $\Delta \rho_{\mathrm{b}}=\sum_{i=1}^{3} \lambda_{i}$, and the ellipticity $\varepsilon=\lambda_{1} / \lambda_{2}-1$. The ellipticity measures the deviation of the charge distribution along the bond path from axial symmetry. The topology of Laplacian of $\rho(\boldsymbol{r})$ is more complicated than that of $\rho(\boldsymbol{r})$ itself; it determines where the field is locally concentrated $\left(\Delta \rho_{\mathrm{b}}\left(r_{\mathrm{c}}\right)<0\right)$ or depleted $\left(\Delta \rho_{\mathrm{b}}\left(r_{\mathrm{c}}\right)>0\right)$. For closed-shell interactions, as found in ionic bonds, hydrogen bonds, and van der Waals molecules, $\Delta \rho_{\mathrm{b}}\left(r_{\mathrm{c}}\right)$ should be positive and $\rho_{\mathrm{b}}\left(r_{\mathrm{c}}\right)$ low. ${ }^{60}$ The topological analysis was carried out using AIMALL program packages. ${ }^{81}$

\section{Preparation of palladium complexes}

Complexes 1-8 were synthesized utilizing the well-known procedures. ${ }^{15,18,25,27,31,32}$ Complexes 10-12 obtained by dissolving of the corresponding palladacycles 4-6 in acetonitrile. Complexes 11, 12 were investigated only in solutions.

[(bhq)Pd(TFA) $]_{2}$ (5). ${ }^{1} \mathrm{H}$ NMR $\left(400.1 \mathrm{MHz}, \mathrm{CD}_{2} \mathrm{Cl}_{2}\right): \delta=7.72$ $(\mathrm{d}, J=5.3 \mathrm{~Hz}, 2 \mathrm{H}) ; 7.61(\mathrm{dd}, J=8.1,1.1 \mathrm{~Hz} ; 2 \mathrm{H}) ; 7.31-7.28$ $(\mathrm{m}, 4 \mathrm{H}) ; 7.17(\mathrm{t}, J=7.7 \mathrm{~Hz}, 2 \mathrm{H}) ; 7.09(\mathrm{~d}, J=8.7 \mathrm{~Hz}, 2 \mathrm{H}) ; 6.86$ $(\mathrm{d}, J=7.6 \mathrm{~Hz}, 2 \mathrm{H}) ; 6.65(\mathrm{dd}, J=8.1,5.3 \mathrm{~Hz} ; 2 \mathrm{H}) .{ }^{13} \mathrm{C} \mathrm{NMR}$ $\left(100.6 \mathrm{MHz}, \mathrm{CD}_{2} \mathrm{Cl}_{2}\right): \delta=167.2 ; 153.4 ; 149.1 ; 146.5 ; 136.9$; $133.4 ; 128.5 ; 128.3 ; 128.2 ; 126.0 ; 123.8 ; 123.6 ; 121.1 ; \mathrm{CF}_{3}$ peak could not be resolved. ${ }^{19} \mathrm{~F}$ NMR $\left(470.6 \mathrm{MHz} ; \mathrm{CD}_{2} \mathrm{Cl}_{2}\right): \delta=$ -72.62. Calcd (\%) for $\mathrm{C}_{30} \mathrm{H}_{16} \mathrm{~F}_{6} \mathrm{~N}_{2} \mathrm{O}_{4} \mathrm{Pd}_{2}$ C: 45.31, H: 2.03, $\mathrm{N}:$ 3.52. Found $\mathrm{C}: 45.35, \mathrm{H}: 2.06, \mathrm{~N}: 3.47$. ESI-MS: $\left[\mathrm{M}+\mathrm{CF}_{3} \mathrm{COOH}\right]^{-}$907; MALDI-MS: [M] 793.

[(phpz)Pd(TFA) $]_{2}$ (6). ${ }^{1} \mathrm{H}$ NMR $\left(500.1 \mathrm{MHz}, \mathrm{CDCl}_{3}\right)$ : isomer 1 $(75 \%) \delta=7.42(\mathrm{~d}, J=2.8 \mathrm{~Hz}, 2 \mathrm{H}) ; 7.02(\mathrm{~d}, J=2.3 \mathrm{~Hz}, 2 \mathrm{H}) ; 6.93$ $(\mathrm{td}, J=7.2,1.7 \mathrm{~Hz} ; 2 \mathrm{H}) ; 6.80-6.75(\mathrm{~m}, 4 \mathrm{H}) ; 6.67(\mathrm{~d}, J=7.8 \mathrm{~Hz}$, $2 \mathrm{H}) ; 5.98(\mathrm{t}, J=2.5 \mathrm{~Hz} ; 2 \mathrm{H})$; isomer $2(25 \%) \delta=7.55(\mathrm{~d}, J=$ $2.8 \mathrm{~Hz}, 2 \mathrm{H}) ; 7.22(\mathrm{~d}, J=2.3 \mathrm{~Hz}, 2 \mathrm{H}) ; 6.83-6.79(\mathrm{~m}, 2 \mathrm{H})$; 6.64-6.55 (m, 6H); $6.21(\mathrm{t}, J=2,4 \mathrm{~Hz} ; 2 \mathrm{H}) .{ }^{13} \mathrm{C} \quad \mathrm{NMR}$ $\left(100.6 \mathrm{MHz}, \mathrm{CD}_{2} \mathrm{Cl}_{2}\right)$ : isomer $1 \delta=141.82 ; 140.01 ; 131.22$; 129.47; 125.36; 125.04; 124.61; $115.54\left(\mathrm{CF}_{3}, \mathrm{q}, J=287.1 \mathrm{~Hz}\right)$; 110.62; 106.73; $\mathrm{C}=\mathrm{O}$ peak could not be resolved; isomer $2 \delta=$ $141.50 ; 139.34 ; 132.04 ; 129.01 ; 125.18 ; 124.97 ; 124.83 ; 110.49$; 106.51; $\mathrm{CF}_{3}$ and $\mathrm{C}=\mathrm{O}$ peaks could not be resolved. ${ }^{19} \mathrm{~F}$ NMR (470.6 MHz; $\left.\mathrm{CDCl}_{3}\right)$ : isomer $1(75 \%) \delta=-72.65$; isomer $2(25 \%) \delta=-72.17,-72.83$. Calcd (\%) for $\mathrm{C}_{22} \mathrm{H}_{14} \mathrm{~F}_{6} \mathrm{~N}_{4} \mathrm{O}_{4} \mathrm{Pd}_{2} \mathrm{C}$ : 36.44, H: 1.95, N: 7.73. Found C: $36.40, \mathrm{H}: 1.97, \mathrm{~N}: 7.69$. ESI-MS: $\left[\mathrm{M}+\mathrm{CF}_{3} \mathrm{COOH}\right]^{-}$839; MALDI-MS: $[\mathrm{M}]^{-} 725$.

(bhq)Pd(TFA)(CH $\left.\mathrm{CH}_{3} \mathrm{CN}\right)$ (11). ${ }^{1} \mathrm{H}$ NMR $\left(400.1 \mathrm{MHz}, \mathrm{CD}_{3} \mathrm{CN}\right)$ : $\delta=8.41($ br., $1 \mathrm{H}) ; 8.34(\mathrm{~d}, J=8.1 \mathrm{~Hz}, 1 \mathrm{H}) ; 7.69-7.57(\mathrm{~m}, 2 \mathrm{H})$; $7.57(\mathrm{~d}, J=7.7 \mathrm{~Hz}, 1 \mathrm{H}) ; 7.49-7.46(\mathrm{~m}, 1 \mathrm{H}) ; 7.33(\mathrm{t}, J=7.5 \mathrm{~Hz}$, 1H); 7.25 (br., $1 \mathrm{H}) ; 1.96$ (s, 3H). ${ }^{13} \mathrm{C}$ NMR (100.6 MHz, $\left.\mathrm{CD}_{3} \mathrm{CN}\right)$ : $\delta=150.0 ; 142.1 ; 139.9 ; 135.0 ; 132.9 ; 130.0 ; 129.9 ; 128.4 ; 125.1$; 125.0; 123.4; $\mathrm{CN}$ and solvent peaks overlap; $\mathrm{CF}_{3}$ and $\mathrm{C}=\mathrm{O}$ peaks could not be resolved. ${ }^{19} \mathrm{~F}$ NMR $\left(470.6 \mathrm{MHz} ; \mathrm{CD}_{3} \mathrm{CN}\right): \delta=$ -73.71. ESI-MS: $\left[\mathrm{M}-\mathrm{CF}_{3} \mathrm{COO}\right]^{+} 325$.

(phpz)Pd(TFA)(CH $\left.\mathbf{C H}_{3} \mathbf{C N}\right)(\mathbf{1 2}) .{ }^{1} \mathrm{H}$ NMR $\left(400.1 \mathrm{MHz}, \mathrm{CD}_{3} \mathrm{CN}\right)$ : $\delta=8.17$ (d, $J=2.6 \mathrm{~Hz}, 1 \mathrm{H}) ; 7.55$ (br., $1 \mathrm{H}) ; 7.22-7.13(\mathrm{~m}, 3 \mathrm{H})$; $6.93(\mathrm{t}, J=7.4 \mathrm{~Hz}, 1 \mathrm{H}) ; 6.49(\mathrm{t}, J=2.5 \mathrm{~Hz}, 1 \mathrm{H}) ; 1.96(\mathrm{~s}, 3 \mathrm{H})$. ${ }^{13} \mathrm{C}$ NMR $\left(100.6 \mathrm{MHz}, \mathrm{CD}_{3} \mathrm{CN}\right): \delta=144.1 ; 141.9 ; 135.9 ; 131.1$; $128.3 ; 127.1 ; 126.5 ; 113.2 ; 108.3 ; \mathrm{CN}$ and solvent peaks overlap; $\mathrm{CF}_{3}$ and $\mathrm{C}=\mathrm{O}$ peaks could not be resolved. ${ }^{19} \mathrm{~F}$ NMR $(470.6 \mathrm{MHz}$; $\mathrm{CD}_{3} \mathrm{CN}$ ): $\delta=-75.14$. ESI-MS: $\left[\mathrm{M}-\mathrm{CF}_{3} \mathrm{COO}\right]^{+} 290$.

\section{X-ray structure determination}

Data set for single crystals 5, 6 and $\mathbf{9}$ were collected on a Bruker AXS Kappa APEX Duo diffractometer with graphitemonochromated Mo $K_{\alpha}$ radiation $(\lambda=0.71073 \AA)$. Programs used: data collection APEX $2,{ }^{82}$ data reduction SAINT, ${ }^{83}$ absorption correction SADABS version $2.10,^{84}$ structure solution SHELXS, ${ }^{85}$ structure refinement by full-matrix least-squares against $F^{2}$ using SHELXL. ${ }^{85}$ Hydrogen atoms were placed into calculated positions and refined as riding atoms. The figures were generated using Mercury 3.1 program. ${ }^{86}$

Three $\mathrm{CF}_{3}$ groups in structure 6 were disordered over two positions and were refined with an occupancy ratio of $0.83: 0.17,0.83: 0.17$ and $0.88: 0.12$.

Crystal data for 5. Formula $\mathrm{C}_{30} \mathrm{H}_{16} \mathrm{~F}_{6} \mathrm{~N}_{2} \mathrm{O}_{4} \mathrm{Pd}_{2}$, crystal size $0.17 \times 0.15 \times 0.09 \mathrm{~mm}^{3}, M_{\mathrm{r}}=795.25$, monoclinic, space group $P 2_{1} / c, a=18.502(6), b=21.414(7), c=13.415(4) \AA, \beta=95.006(4)^{\circ}$, $V=5295(3) \AA^{3}, Z=8, \rho_{\mathrm{c}}=1.995 \mathrm{~g} \mathrm{~cm}^{-3}, \mu=1.443 \mathrm{~mm}^{-1}$, 
$T=150(2) \mathrm{K}, \theta$ range $=1.796^{\circ}$ to $28.500^{\circ}$, reflections collected 110098 ; independent: $13392\left(R_{\text {int }}=0.0699\right)$ and 10914 observed reflections $[I>2(I)], 793$ refined parameters, $R_{1}=$ $0.0275, \mathrm{w} R_{2}=0.0599[I>2 \sigma(I)]$; maximal residual electron density: $0.61 /-0.88$ e $\AA^{-3}$.

Crystal data for 6. Formula $\mathrm{C}_{22} \mathrm{H}_{14} \mathrm{~F}_{6} \mathrm{~N}_{4} \mathrm{O}_{4} \mathrm{Pd}_{2}$, crystal size $0.22 \times 0.14 \times 0.12 \mathrm{~mm}^{3}, M_{\mathrm{r}}=725.17$, monoclinic, space group $P 2_{1} / c, a=26.848(1), b=12.1003(7), c=22.879(1) \AA, \beta=93.201(1)^{\circ}$, $V=7421.1(6) \AA^{3}, Z=12, \rho_{\mathrm{c}}=1.947 \mathrm{~g} \mathrm{~cm}^{-3}, \mu=1.536 \mathrm{~mm}^{-1}, T=$ $150(2) \mathrm{K}, \theta$ range $=1.519^{\circ}$ to $26.372^{\circ}$, reflections collected 132517 ; independent: $15176\left(R_{\mathrm{int}}=0.0473\right)$ and 12479 observed reflections $[I>2(I)], 1063$ refined parameters, $R_{1}=$ $0.0296, \mathrm{w} R_{2}=0.0678[I>2 \sigma(I)]$; maximal residual electron

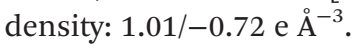

Crystal data for 9. Formula $\mathrm{C}_{34} \mathrm{H}_{36} \mathrm{~N}_{2} \mathrm{O}_{6} \mathrm{P}_{2} \mathrm{Pd}_{2}$, crystal size $0.31 \times 0.21 \times 0.18 \mathrm{~mm}^{3}, M_{\mathrm{r}}=843.39$, triclinic, space group $P \overline{1}$, $a=10.197(1), b=13.081(1), c=13.311(2) \AA, \alpha=107.243(3)^{\circ}, \beta=$ 93.614(3) ${ }^{\circ}, \gamma=110.812(3)^{\circ}, V=1556.6(3) \AA^{3}, Z=2, \rho_{\mathrm{c}}=1.799 \mathrm{~g}$ $\mathrm{cm}^{-3}, \mu=1.309 \mathrm{~mm}^{-1}, T=100(2) \mathrm{K}, \theta$ range $=1.631^{\circ}$ to $26.372^{\circ}$, reflections collected 39612 ; independent: $6365\left(R_{\text {int }}=\right.$ $0.0399)$ and 5463 observed reflections $[I>2(I)], 419$ refined parameters, $R_{1}=0.0439, \mathrm{w}_{2}=0.0963[I>2 \sigma(I)]$; maximal

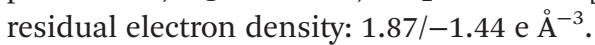

Crystallographic data for the structural analysis of compounds 5, 6, 9 has been deposited at the Cambridge Crystallographic Data Center (CCDC numbers 14888601488862).

\section{Conclusions}

Thus, in this work a combination of electrochemical techniques, ESR spectroscopy and quantum chemical calculations in the study of a series of cyclometalated $\operatorname{Pd}($ II) complexes was used to reveal the dependence of their electrochemical properties on their structures. Namely, the longer distance and weaker interaction between two palladium centers in a molecule, the higher oxidation potential value. Monomeric palladacycles are oxidized more difficult than dimeric ones; phosphonate palladacycles are oxidized more difficult than acetate ones, and etc.

The regularity is an important step in understanding the reactivity of cyclometalated palladium(II) complexes in catalytic reactions, particularly ligand-directed oxidative organic functionalizations. An important problem that has to be solved to organize a successful catalytic cycle for $\mathrm{Pd}(\mathrm{II})$-catalyzed $\mathrm{C}-\mathrm{H}$ functionalizations of arenic substrates is the selection of an appropriate oxidizing agent. The oxidant has to be effective in oxidation of $\mathrm{Pd}(\mathrm{II})$ into $\mathrm{Pd}(\mathrm{III}) / \mathrm{Pd}(\mathrm{IV})$ intermediates which turn into the final products in reduction elimination step. Knowledge of oxidation potentials of these important intermediates and comparison study of redox trends of cyclopalladated complexes depending on ligand environment of the metal simplify the control over the catalytic reaction, that is very important in processes where several possible intermediates with different oxidation potentials are present. The adequate choice of the oxidation potential (or a chemical oxidant) minimize or even prevents formation of byproducts in these reactions.

The more positive oxidation potential of a palladacycle, the slower its oxidation into $\mathrm{Pd}(\mathrm{III}) /(\mathrm{Iv})$ intermediates under the action of an adopted chemical oxidant, considering all other conditions being equal. However, as the CV and ESR experiments shown the higher oxidation potentials, the less stable the high-valent intermediates and the faster reductive elimination rates. Certainly, the observed regularity is not a rule but a trend revealing the change in palladacycles redox properties with their structure.

\section{Acknowledgements}

This work was supported by the Russian Science Foundation (grant no. 14-23-00016).

\section{References}

1 E. Negishi and A. de Meijere, Handbook of Organopalladium Chemistry for Organic Synthesis, 2 Vol. Set, Wiley-VCH, Hoboken, 2002.

2 X. Chen, K. M. Engle, D.-H. Wang and J.-Q. Yu, Angew. Chem., Int. Ed., 2009, 48, 5094-5115.

3 A. Jutand, Chem. Rev., 2008, 108, 2300-2347.

4 D. C. Powers and T. Ritter, Top. Organomet. Chem., 2011, 35, 129-156.

5 J. M. Racowski and M. S. Sanford, Top. Organomet. Chem., 2011, 35, 61-84.

6 S. R. Neufeldt and M. S. Sanford, Acc. Chem. Res., 2012, 45, 936-946.

7 T. W. Lyons and M. S. Sanford, Chem. Rev., 2010, 110, 1147-1169.

8 C. Li, T. Yano, N. Ishida and M. Murakami, Angew. Chem., Int. Ed., 2013, 52, 9801-9804.

9 Ch.-G. Feng, M. Ye, K.-J. Xiao, S. Li and J.-Q. Yu, J. Am. Chem. Soc., 2013, 135, 9322-9325.

10 Y. Ye, N. D. Ball, J. W. Kampf and M. S. Sanford, J. Am. Chem. Soc., 2010, 133, 14682-14687.

11 Q. Dang, Y. Liu, D. K. Cashion, S. R. Kasibhatla, T. Jiang, F. Taplin, J. D. Jacintho, H. Li, Z. Sun, Y. Fan, J. DaRe, F. Tian, W. Li, T. Gibson, R. Lemus, P. D. van Poelje, S. C. Potter and M. D. Erion, J. Med. Chem., 2011, 54, 153-165.

12 X. Chen, D. J. Kopecky, J. Mihalic, S. Jeffries, X. Min, J. Heath, J. Deignan, S. Lai, Z. Fu, C. Guimaraes, S. Shen, S. Li, S. Johnstone, S. Thibault, H. Xu, M. Cardozo, W. Shen, N. Walker, F. Kayser and Z. Wang, J. Med. Chem., 2012, 55, 3837-3851.

13 P. Kirsch, Modern Fluoroorganic Chemistry: Synthesis, Reactivity, Applications, Wiley-VCH, Weinheim, 2004.

14 K. Müller, C. Faeh and F. Diederich, Science, 2007, 317, 1881-1886. 
15 D. C. Powers, M. A. L. Geibel, J. E. M. N. Klein and T. Ritter, J. Am. Chem. Soc., 2009, 131, 17050-17051.

16 M. G. Campbell, D. C. Powers, J. Raynaud, M. J. Graham, P. Xie, E. Lee and T. Ritter, Nat. Chem., 2011, 3, 949-953.

17 J. E. Bercaw, A. C. Durrell, H. B. Gray, J. C. Green, N. Hazari, J. A. Labinger and J. R. Winkler, Inorg. Chem., 2010, 49, 1801-1810.

18 Y. B. Dudkina, D. Y. Mikhaylov, T. V. Gryaznova, A. I. Tufatullin, O. N. Kataeva, D. A. Vicic and Y. H. Budnikova, Organometallics, 2013, 32, 4785-4792.

19 B. N. Nguyen, L. A. Adrio, T. Albrecht, A. J. P. White, M. A. Newton, M. Nachtegaal, S. J. A. Figueroa and K. K. Hii, Dalton Trans., 2015, 44, 16586-16591.

20 A. Ariafard, C. J. T. Hyland, A. J. Canty, M. Sharma and B. F. Yates, Inorg. Chem., 2011, 50, 6449-6457.

21 R. Giri, Y. Lan, P. Liu, K. N. Houk and J.-Q. Yu, J. Am. Chem. Soc., 2012, 134, 14118-14126.

22 A. J. Canty, A. Ariafard, M. S. Sanford and B. F. Yates, Organometallics, 2013, 32, 544-555.

23 M. C. Nielsen, E. Lyngvi and F. Schoenebeck, J. Am. Chem. Soc., 2013, 135, 1978-1985.

24 D. C. Powers, E. Lee, A. Ariafard, M. S. Sanford, B. F. Yates, A. J. Canty and T. Ritter, J. Am. Chem. Soc., 2012, 134, 12002-12009.

25 B. E. Haines, J. F. Berry, J.-Q. Yu and D. G. Musaev, ACS Catal., 2016, 6, 829-839.

26 A. R. Dick, K. L. Hull and M. S. Sanford, J. Am. Chem. Soc., 2004, 126, 2300-2301.

27 J. E. Bercaw, A. C. Durrell, H. B. Gray, J. C. Green, N. Hazari, J. A. Labinger and J. R. Winkler, Inorg. Chem., 2010, 49, 1801-1810.

28 D. C. Powers and T. Ritter, Nat. Chem., 2009, 1, 302-309.

29 J. L. Serrano, L. García, J. Pérez, E. Pérez, J. M. Galiana, J. García, M. Martínez, G. Sánchez and I. da Silva, Dalton Trans., 2011, 40, 156-168.

30 N. Marino, C. H. Fazen, J. D. Blakemore, C. D. Incarvito, N. Hazari and R. P. Doyle, Inorg. Chem., 2011, 50, 25072520.

31 T. V. Grayaznova, Yu. B. Dudkina, D. R. Islamov, O. N. Kataeva, O. G. Sinyashin, D. A. Vicic and Yu. H. Budnikova, J. Organomet. Chem., 2015, 785, 68-71.

32 T. Gryaznova, Yu. Dudkina, M. Khrizanforov, O. Sinyashin, O. Kataeva and Yu. Budnikova, J. Solid State Electrochem., 2015, 19, 2665-2672.

33 T. Pawlak, D. Niedzielska, J. Vícha, R. Marek and L. Pazderski, J. Organomet. Chem., 2014, 759, 58-66.

34 G. J. Chuang, W. Wang, E. Lee and T. Ritter, J. Am. Chem. Soc., 2011, 133, 1760-1762.

35 F. A. Cotton, J. Gu, C. A. Murillo and D. J. Timmons, J. Am. Chem. Soc., 1998, 120, 13280-13281.

36 F. A. Cotton, M. Matusz, R. Poli and X. Feng, J. Am. Chem. Soc., 1988, 110, 1144-1154.

37 J. F. Berry, F. A. Cotton, S. A. Ibragimov, C. A. Murillo and X. Wang, Inorg. Chem., 2005, 44, 6129-6137.

38 J. F. Berry, E. Bill, E. Bothe, F. A. Cotton, N. S. Dalal, S. A. Ibragimov, N. Kaur, C. Y. Liu, C. A. Murillo,
S. Nellutla, J. M. North and D. Villagrán, J. Am. Chem. Soc., 2007, 129, 1393-1401.

39 C. L. Yao, L. P. He, J. D. Korp and J. L. Bear, Inorg. Chem., 1988, 27, 4389-4395.

40 M. G. Campbell, S.-L. Zheng and T. Ritter, Inorg. Chem., 2013, 52, 13295-13297.

41 L. M. Mirica and J. R. Khusnutdinova, Coord. Chem. Rev., 2013, 257, 299-314.

42 B. R. Patyal, B. L. Scott and R. D. Willett, Phys. Rev. B: Condens. Matter, 1990, 41, 1657-1663.

43 V. I. Krinichnyi, Appl. Phys. Rev., 2014, 1, 021305.

44 C. M. Cardona, W. Li, A. E. Kaifer, D. Stockdale and G. C. Bazan, Adv. Mater., 2011, 23, 2367-2371.

45 A. Dadvand, F. Cicoira, K. Yu. Chernichenko, E. S. Balenkova, R. M. Osuna, F. Rosei, V. G. Nenajdenko and D. F. Perepichka, Chem. Commun., 2008, 5354-5356.

46 Y. Liang, Z. Xu, J. Xia, S. T. Tsai, Y. Wu, G. Li, C. Ray and L. Yu, Adv. Mater., 2010, 22, E135-E138.

47 L. J. Huo, J. H. Hou, S. Q. Zhang, H. Y. Chen and Y. Yang, Angew. Chem., Int. Ed., 2010, 49, 1500-1503.

48 C. Hsiang-Yu, H. Jianhui, Z. Shaoqing, L. Yongye, Y. Guanwen, Y. Yang, Y. Luping, W. Yue and L. Gang, Nat. Photonics, 2009, 3, 649-653.

49 Y. Liang, D. Feng, Y. Wu, S.-T. Tsai, G. Li, C. Ray and L. Yu, J. Am. Chem. Soc., 2009, 131, 7792-7799.

50 Y. Liang, Y. Wu, D. Feng, S.-T. Tsai, H.-J. Son, G. Li and L. Yu, J. Am. Chem. Soc., 2009, 131, 56-57.

51 C. T. Campos and F. E. Jorge, Mol. Phys., 2013, 111, 167-173.

52 C. L. Barros, P. J. P. de Oliveira, F. E. Jorge, A. Canal Neto and M. Campos, Mol. Phys., 2010, 108, 1965-1972.

53 F. E. Jorge, A. Canal Neto, G. G. Camilett and S. F. Machado, J. Chem. Phys., 2009, 130, 064108.

54 J. Tomasi, B. Mennucci and R. Cammi, Chem. Rev., 2005, 105, 2999-3093.

55 W. Ramsay and R. Foster, Nature, 1949, 163, 178-179.

56 R. E. Ballard, Chem. Phys. Lett., 1976, 42, 97-98.

57 L. L. Miller, G. D. Nordblom and E. A. Mayeda, J. Org. Chem., 1972, 37, 916-918.

58 W. C. Neikam, G. R. Dimeler and M. M. Desmond, J. Electrochem. Soc., 1964, 111, 1190-1192.

59 A. J. Bard and L. R. Faulkner, Electrochemical Methods: Fundamentals and Applications, Wiley, New York, 2001.

60 R. F. W. Bader, Atoms in Molecules: A Quantum theory, Oxford University Press, New York, 1990.

61 L. Estévez, N. Otero and R. A. Mosquera, J. Phys. Chem. A, 2009, 113, 11051-11058.

62 W. Nakanishi, S. Hayashi and K. Narahara, J. Phys. Chem. A, 2008, 112, 13593-13599.

63 K. Kholin, M. Valitov, V. Burilov, E. Tselischeva, S. Strekalova, A. Mustafina, Yu. Budnikova and M. Kadirov, Electrochim. Acta, 2015, 182, 212-216.

64 S. Šoralova, M. Breza and M. Grof, Polyhedron, 2011, 30, 307-314.

65 E. Derat and G. Maestri, Wiley Interdiscip. Rev.: Comput. Mol. Sci.., 2013, 3, 529-541. 
66 K. Arumugam and U. Becker, Minerals, 2014, 4, 345-387.

67 P. Jaque, A. V. Marenich, C. J. Cramer and D. G. Truhlar, J. Phys. Chem. C, 2007, 111, 5783-5799.

68 M.-H. Baik; and R. A. Friesner, J. Phys. Chem. A, 2002, 106, 7407-7412.

69 K. A. Peterson, D. Figgen, M. Dolg and H. Stoll, J. Chem. Phys., 2007, 126, 124101.

70 D. Figgen, K. A. Peterson and H. Stoll, J. Chem. Phys., 2008, 128, 034110.

71 K. A. Peterson, J. Chem. Phys., 2003, 119, 11099-11112.

72 K. A. Peterson, D. Figgen, E. Goll, H. Stoll and M. Dolg, J. Chem. Phys., 2003, 119, 11113-11123.

73 A. V. Zaitsevskii, C. van Wüllen and A. V. Titov, Russ. Chem. Rev., 2009, 78, 1173-1181.

74 M. Iliaš, V. Kellö and M. Urban, Acta Phys. Slovaca, 2010, 60, 259-391.

75 S. Wilson, Electron correlation in Molecules, Oxford University Press, Oxford, 1984.

76 EMSL Basis set Exchange, https://bse.pnl.gov/bse/portal.

77 M. Douglas and N. M. Kroll, Ann. Phys., 1974, 82, 89-155.

78 B. A. Hess, Phys. Rev. A, 1985, 32, 756-763.

79 B. A. Hess, Phys. Rev. A, 1986, 33, 3742-3748.

80 M. J. Frisch, G. W. Trucks, H. B. Schlegel, G. E. Scuseria, M. A. Robb, J. R. Cheeseman, G. Scalmani, V. Barone, B. Mennucci, G. A. Petersson, H. Nakatsuji, M. Caricato, X. Li, H. P. Hratchian, A. F. Izmaylov, J. Bloino, G. Zheng, J. L. Sonnenberg, M. Hada, M. Ehara, K. Toyota, R. Fukuda,
J. Hasegawa, M. Ishida, T. Nakajima, Y. Honda, O. Kitao, H. Nakai, T. Vreven, J. A. Montgomery Jr., J. E. Peralta, F. Ogliaro, M. Bearpark, J. J. Heyd, E. Brothers, K. N. Kudin, V. N. Staroverov, R. Kobayashi, J. Normand, K. Raghavachari, A. Rendell, J. C. Burant, S. S. Iyengar, J. Tomasi, M. Cossi, N. Rega, J. M. Millam, M. Klene, J. E. Knox, J. B. Cross, V. Bakken, C. Adamo, J. Jaramillo, R. Gomperts, R. E. Stratmann, O. Yazyev, A. J. Austin, R. Cammi, C. Pomelli, J. W. Ochterski, R. L. Martin, K. Morokuma, V. G. Zakrzewski, G. A. Voth, P. Salvador, J. J. Dannenberg, S. Dapprich, A. D. Daniels, Ö. Farkas, J. B. Foresman, J. V. Ortiz, J. Cioslowski and D. J. Fox, Gaussian, Inc., Wallingford, CT, 2009.

81 T. A. Keith, AIMALL, version 09.04.23, TK Gristmill Software, 2009.

82 Bruker, APEX2 Software Suite for Crystallographic Programs, Bruker AXS, Inc., Madison, WI, USA, 2009.

83 Bruker, Area detector control and integration software, Version 5.1, In SMART and SAINT, Bruker Analytical X-ray Instruments Inc., Madison, Wisconsin, USA, 1996.

84 M. Sheldrick, SADABS. Program for absorption correction, University of Goettingen, Germany, 1996.

85 G. M. Sheldrick, Acta Crystallogr., Sect. A: Fundam. Crystallogr., 2008, 64, 112-122.

86 C. F. Macrae, P. R. Edgington, P. McCabe, E. Pidcock, G. P. Shields, R. Taylor, M. Towler and J. van de Streek, J. Appl. Crystallogr., 2006, 39, 453-457. 